\title{
Paleoecologia do sistema Pinguela-Palmital-Malvas, Holoceno da Bacia de Pelotas, RS, Brasil: uma abordagem focada na utilização de análises multivariadas para obtenção de diatomáceas descritoras
}

\author{
Guilherme HERMANY1 , Paulo A. SOUZA² \& Lezilda CarvalhoTORGAN ${ }^{3}$
}

1Escola Municipal de Educação Básica Dr. Liberato Salzano Vieira da Cunha. Rua Xavier de Carvalho, 274, CEP 91.110-440, Porto Alegre, RS Brasil. E-mail: guilherme.hermany@gmail.com.

2Instituto de Geociências, Universidade Federal do Rio Grande do Sul. Av. Bento Gonçalves, 9.500, CEP 91.540-000, Porto Alegre, RS, Brasil. E-mail: paulo.alves.souza@ufrgs.br.

3Fundação Zoobotânica do Rio Grande do Sul, Museu de Ciências Naturais, Seção de Botânica de Criptógamas. Rua Salvador França, 1.427, CEP 90.690-000, Porto Alegre, RS, Brasil. E-mail: lezilda-torgan@fzb.rs.gov.br.

Recebido em 04/2012. Aceito para publicação em 01/2013.

Versão online publicada em 06/09/2013 (www.pesquisasemgeociencias.ufrgs.br)

\begin{abstract}
Resumo - Este trabalho foi desenvolvido visando reconstituir os sucessivos paleoambientes do sistema lacustre Pinguela-Palmital-Malvas na porção emersa norte da Bacia de Pelotas, durante o Holoceno com base em diatomáceas, a partir de 89 amostras do testemunho de sondagem PM-RS-D01 com 4,87 m de profundidade total. Maior objetividade dentro deste enfoque foi obtida pela definição de espécies indicadoras de conjuntos de unidades amostrais oriundos de níveis de particionamentos significativos em análises de agrupamento. Os resultados demonstraram que, entre $4.600 \pm 70$ anos AP e 3.950 \pm 70 anos AP, ocorre alternância entre estratos compostos pela preponderância de espécies mixohalinas e intervalos caracterizados pela supremacia de espécies dulciaqüícolas em um contexto transgressivo; os registros determinados por Actinocyclus normanii refletem períodos de clima mais seco, quando o volume de água doce drenado para a bacia era menor e a evaporação mais intensa. De forma inversa, Aulacoseira cf. agassizii determinou o esclarecimento de etapas de incremento do afluxo lótico por variação positiva do regime pluviométrico. Após $3.950 \pm 70$ anos A.P., alterações sedimentológicas e bióticas significativas como o estabelecimento de fácies com predomínio de areia e a maior diversidade e abundância de vestígios de espécies perifíticas, caracterizam o início do processo de regressão holocena da planície costeira gaúcha. A manutenção da coerência das interpretações paleoambientais obtidas, quando confrontadas a estudos pregressos, e a detecção de processos originais para a região, assinalam a eficiência dos procedimentos estatísticos empregados baseados no estabelecimento de agrupamentos significativos e destaque a espécies descritoras destes particionamentos.
\end{abstract}

Palavras-chave: Holoceno, planície costeira, Rio Grande do Sul, análises multivariadas, diatomáceas fósseis.

\begin{abstract}
Paleoecology of the Pinguela-Palmital-Malvas System, Holocene of the Pelotas Basin, RS, BRAZIL: AN APPROACH FOCUSED ON THE USE OF MULTIVARIATE ANALYSIS FOR OBTAINING DIATOMS AS PALEOENVIRONMENTAL DESCRIPTORS. This work was conducted aiming to reconstitute paleoenvironments of the lacustrine Pinguela-Palmital-Malvas System, placed on the emerged portion north of Pelotas Basin during the Holocene. This study is based on 89 subsurface samples from the PM-RS-D01 core (4.87 m of total depth), using diatoms as descriptors. Thus, a better objectivity was obtained by defining the species indicative of sets of sampling units originated from levels of significant partitioning in grouping analyses. Between $4.600 \pm 70$ years BP and $3.950 \pm$ years BP, an alternation occurred between strata constituted predominantly by mixohaline diatoms and intervals characterized by supremacy of freshwater species in a transgressive context; records of Actinocyclus normanii reflect periods of a drier climate as the volume of fresh water drained into the basin was smaller and evaporation was more intense. On the contrary, Aulacoseira cf. agassizii determined the clarification on stages of increment of the lotic influx through positive variation of intensive pluviometric regime. After $3.950 \pm 70$ years AP, significant sedimentological and biotic alterations, like as the establishment of facies with sandy and greater diversity and abundance of signs of periphytic species characterize the beginning of the Holocene regression process of these Coastal Plains. The maintenance of these coherent paleoenvironmental interpretations, compared with previous studies, and the discovery of original processes for the region show the efficiency of the statistical procedures here used, based on the establishment of significant groupings and the prominence of descriptor species from this partitioning.
\end{abstract}

Keywords: Holocene, coastal plain, Rio Grande do Sul, multivariate analysis, fossil diatoms. 


\section{Introdução}

Os estudos paleoecológicos holocenos realizados na Planície Costeira Norte do Rio Grande do Sul fundamentam-se, em sua maioria, na análise de grãos de pólens e esporos. Embora constituam paleoindicadores valiosos, sua distribuição e abundância ao longo dos testemunhos são controlados diretamente pelas variações climáticas. Portanto, inferências mais específicas a respeito de características ambientais locais, como o grau de salinidade da massa d'água, foram obtidas por geoquímica ou pelo exame de palinofácies, incluindo algas de parede orgânica (clorofíceas e dinoflagelados) e acritarcos (p.ex. Medeanic et al., 2000a, 2000b, 2001; Medeanic \& Dillenburg, 2001; Marques-Toigo et al., 2002; Weschenfelder et al., 2008), não tendo sido consideradas por esses autores as diatomáceas.

As diatomáceas são as produtoras primárias mais abundantes dos ecossistemas aquáticos, e estão expressivamente representadas nos sedimentos. A distinção entre espécies dulcícolas, mixohalinas e marinhas está amplamente estabelecida (p. ex. Long, 1992) e, no mesmo patamar, encontra-se o conhecimento correspondente ao hábito dos táxons, algo fundamental para deduções paleoclimáticas (p. ex. Douglas \& Smol, 1999). Estes dois tópicos, aliados ao volume crescente de estudos que versam sobre o comportamento das diatomáceas frente ao pH e nível trófico (Stoermer \& Smol, 1999) permitem a compreensão mais precisa dos paleoambientes, cuja origem e duração podem ser relacionados com eventos de maior escala quando acompanhadas de controle temporal (p. ex. datações absolutas).

São inúmeros os levantamentos realizados em diversas instituições do Brasil com vistas ao entendimento da ecologia das diatomáceas, constituindo um valioso banco de dados aplicável às análises paleontológicas, especialmente no Holoceno (p. ex. Fürstenberger\& Moro, 1998). Neste sentido, no Rio Grande do Sul, Villwock et al. (1980) estudaram turfeiras holocenas do nordeste da Planície Costeira, e constataram a presença de uma descontínua e delgada camada de diatomito, com predomínio de gêneros de água doce, sobre os depósitos de turfa. Abreu et al. (1987) examinaram diatomáceas, bivalves e ostracodes de quatro amostras provenientes de um testemunho de sondagem obtido no município de Triunfo, próximo à confluência dos rios Caí e Jacuí, encontrando espécies de águas salobras. Callegaro \& Lobo (1990) analisaram a distribuição de diatomáceas em amostras superficiais de seis perfurações ao longo da turfeira de Águas Claras. Medeanic et al. (2000a) e Marques-Toigo et al. (2002) classificaram gêneros de algas fósseis das divisões Chlorophyta, Chrysophyta e Bacillariophyta em função da tolerância à salinidade, e identificaram três estágios relacionados com as transgressões e regressões do Atlântico em um testemunho localizado no vale do Rio Maquiné. Este mesmo enfoque, aliado ao estudo de grãos de pólen e esporos, permitiu, no mesmo ano, a Medeanic et al. (2000b) estabelecerem mudanças ambientais causadas por oscilações climáticas e do nível médio do mar na Lagoa dos Patos e adjacências no Holoceno.

Na mesma região, Medeanic \& Dillenburg (2001) identificaram o início da influência marinha pós-glacial na Lagoa dos Patos por volta de 9.620 AP, enquanto uma importante transgressão em torno de $7.350 \mathrm{AP}$ foi registrada por Medeanic et al. (2001). Nestas pesquisas, grãos de pólen, esporos e microalgas de parede orgânica constituíram elementos descritores, juntamente com gêneros e espécies a confirmar de diatomáceas identificações genéricas e a confirmar de espécies de diatomáceas. Uma abordagem micropaleontológica similar, acrescida do estudo de microforaminíferos, foi utilizada por Weschenfelder et al. (2008) em estudo que resultou na detecção de um paleocanal holoceno ligando a Lagoa dos Patos ao Oceano Atlântico.

Excetuando-se Callegaro \& Lobo (1990) e Medeanic et al. (2009), todos os trabalhos supramencionados valeram-se da utilização de diatomáceas fósseis como elemento complementar de análise indicando, de maneira geral, as preferências halóbias dos táxons para a determinação da influência marinha no paleoambiente. É inegável que este enfoque constitui uma aplicação útil das diatomáceas em análises paleoambientais; contudo, no momento em que se objetiva, por exemplo, relacionar movimentos eustáticos com o comportamento de outras variáveis como $\mathrm{pH}$, trofia e alterações batimétricas, o potencial indicativo das diatomáceas é ressaltado, e na comparação direta com a performance de outros grupos algais em estudos paleolimnológicos, ocorre um evidente favorecimento dessas em virtude do extenso conhecimento a respeito de seus requerimentos ecológicos específicos (Stoermer \& Smol, 1999).

No que tange o processamento dos dados, nos estudos paleoecológicos com diatomáceas efetivados na Planície Costeira do Rio Grande do Sul, a definição de biozonas fundamentou-se em critérios subjetivos dos pesquisadores já que, ressalvando Callegaro \& Lobo (1990), não são mencionados procedimentos estatísticos de exame dos resultados quantitativos.

Ao se referir a pesquisas do registro polínico, Bennett (1996) argumenta que sequências de dados estratigráficos são difíceis de descrever e interpretar sem alguma redução para unidades mais gerenciáveis, cujo intuito seria o de identificar zonas de conteúdo uniforme. Neste sentido, a análise de agrupamento, procedimento analítico corriqueiro em pesquisas ecológicas efetuadas no presente (p. ex. Bini, 2004), é uma ferramenta útil para o reconhecimento mais claro e sintético possível da estrutura de conjuntos de níveis estratigráficos definidos pelo arranjo hierárquico das unidades em função de similaridades bióticas.

Meyer et al. (2005) realizaram importante contribuição na área de estudo, ao utilizarem a análise de agrupamentos para identificar seis conjuntos de amos- 
tras que, plotados estratigraficamente, distinguiram três intervalos com palinofácies características em um testemunho de sondagem na Lagoa dos Quadros, RS.

Conforme destacado em Pillar (1999), embora esteja fundamentada em algoritmos matemáticos, para se obter uma classificação a partir dos testes de agrupamento, o investigador precisa escolher, muitas vezes de forma subjetiva, um nível adequado de partição dos grupos. Ademais, as análises de agrupamento sempre revelarão conjuntos, mesmo que o banco de dados não possua estrutura que justifique alguma distinção. Para reduzir a imprecisão no processo de escolha do nível de partição o autor desenvolveu uma técnica, até então não aplicada ao contexto dos estudos paleoecológicos envolvendo descritores algálicos, para testar estatisticamente a nitidez das divisões em análises de agrupamentos utilizando aleatorização e autoreamostragem. Se conjugada a análises que visam caracterizar unidades amostrais de acordo com espécies indicadoras (p. ex. Dufrêne \& Legendre, 1997), esta técnica se constitui em instrumental matemático potencial para definição objetiva de biozonas em estudos do Quaternário.

Neste contexto, este trabalho fundamenta-se metodologicamente no conhecimento pregresso da autoecologia das espécies, de acordo com o registro bibliográfico de estudos nacionais e internacionais. Uma maior objetividade dentro deste enfoque foi obtida pela definição de espécies indicadoras de conjuntos de unidades amostrais oriundas de níveis de particionamentos significativos em análises de agrupamento, prática importada do estudo da ecologia de espécies atuais. Desta forma, um pequeno número de espécies representativas para determinado intervalo estratigrá- fico atuou como descritor, a partir das quais inferências paleoambientais puderam ser desenvolvidas.

\section{2 Área, materiais e métodos}

Para este estudo foram utilizadas 89 amostras de sedimentos provenientes do testemunho de sondagem de 4,87 m denominado PM-RS-D01 (UTM 0583011, 6701449), obtido no pontal de direção noroeste-sudeste que divide as lagoas das Malvas e Palmital, entre os municípios de Maquiné e Osório (Fig. 1). Estas lagoas estão geneticamente relacionadas ao "Sistema Laguna-Barreira IV", desenvolvida sobre a Planície Costeira do Rio Grande do Sul (PCRS), constituindo a porção superior e aflorante da Bacia de Pelotas (Tomazelli \& Villwock, 2000).

A Bacia de Pelotas ocupa uma área de 210.000 $\mathrm{km}^{2}$ na margem continental brasileira, até a isóbata de $2.000 \mathrm{~m}$, dentro dos quais $40.000 \mathrm{~km}^{2}$ constituem a PCRS. Com direção geral NE-SW, localiza-se entre os paralelos $28^{\circ} \mathrm{S}$ e $34^{\circ} \mathrm{S}$, limitada ao norte pelo Alto de Florianópolis e ao sul pela fronteira com o Uruguai, onde passa a receber a denominação de Cuenca del Leste, estendendo-se até o alto do embasamento La Coronilla (Dias et al., 1994). Sua origem está relacionada aos eventos tectônicos ocorridos durante o Eocretáceo e que provocaram a abertura do Atlântico.

A PCRS formou-se durante o Quaternário, a partir do desenvolvimento de um amplo sistema de leques aluviais, na parte mais interna, e o acréscimo de quatro sistemas deposicionais do tipo Laguna-Barreira (Tomazelli \& Villwock, 2000). 0 mais recente, denominado Sistema Laguna-Barreira IV, está relacionado ao estágio

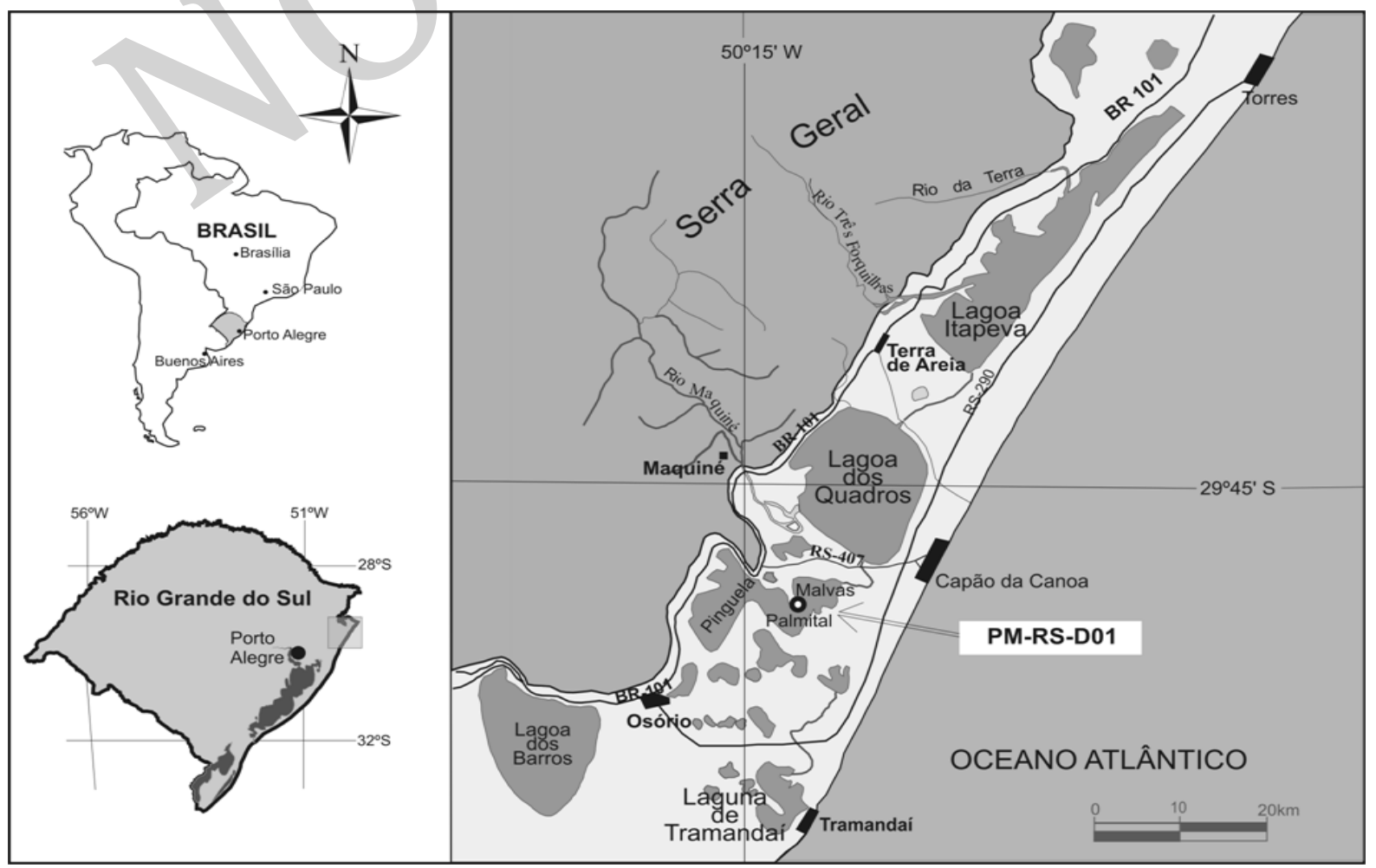

Figura 1. Mapa de localização do testemunho de sondagem PM-RS-D01 (Sistema Pinguela-Palmital-Malvas) na Planície Costeira Norte do Rio Grande do Sul. 
isotópico do oxigênio 1 , no contexto da última transgressão marinha, que atingiu seu máximo em torno de 5.100 AP. De acordo com Tomazelli \& Villwock (1991), o desenvolvimento gradual de uma barreira arenosa a partir daquele momento foi o responsável pelo isolamento dos terrenos continentais pleistocenos do mar, que determinou um sistema deposicional intrincado composto por diversos ambientes, em especial os lagunares, cuja distribuição espacial variou ao longo destes últimos 5.100 anos, devido principalmente a flutuações relativas do nível do mar.

Neste estudo, a denominação de Planície Costeira Norte do Rio Grande do Sul (PCNRS), corresponde à porção delimitada à oeste pela escarpa da Serra Geral, à leste pelo Oceano Atlântico, ao norte pelo município de Torres e, ao sul, pelo município de Tramandaí (Fig. 1). Esta região é caracterizada por uma sequência de cordões sedimentares longitudinais, paralelos à costa, em direção à Serra Geral, onde na interface terra-mar, encontram-se dunas primárias, secundárias e terciárias, seguidas de uma faixa de lagoas (Pedrozo \& Rocha, 2007) (Fig. 1).

As lagoas da PCNRS, em sua maioria, se interconectam por meio de canais meandrantes interlagunares cuja drenagem escoa no sentido da laguna de Tramandaí (Fig. 1). 0 crescimento de pontais com direção NW-SE, que segmentam total ou parcialmente os corpos lagunares, constituem-se de cristas de praias lagunares resultantes da ação do vento dominante (NE) que atinge a superfície dos lagos. Ondas e correntes, originárias da ação deste vento, transportam o material arenoso na direção SE formando as cristas, que se desenvolvem perpendicularmente à direção dominante do vento (Tomazelli \& Villwock, 1991).

Conforme visualizado na figura 1 , as lagoas Pinguela, Palmital e Malvas não se apresentam segmentadas e podem ser consideradas como um único ambiente. Por este motivo, Machado (2001) denominou estes corpos hídricos de "Sistema Pinguela-Palmital-Malvas", com área superficial de $50,07 \mathrm{~km}^{2}$, profundidade média de 1,78 m e máxima de $3,80 \mathrm{~m}$.

Além dos canais meandrantes interlagunares, os rios Maquiné e Três Forquilhas (Fig. 1), cujas cabeceiras estão nos vales da Serra Geral, exercem importante influência na dinâmica dos lagos costeiros. As precipitações nas áreas drenadas por estes rios alcançam valores relativamente elevados, devido, em grande parte, ao efeito de "barreira" ocasionado pela escarpa da Serra Geral na condensação das massas de ar provenientes do mar (Hasenack \& Ferraro, 1989).

Segundo Schwarzbold \& Schäfer (1984), o clima da região é do tipo Cfa ou subtropical úmido, na classificação de Köppen, com distribuição de chuva o ano inteiro, verão quente e inverno frio. A região, que está sob a influência das massas de ar originadas no Anticiclone do Atlântico e no Anticiclone Migratório Polar, possui uma média anual de temperatura de $17,6{ }^{\circ} \mathrm{C}$ e uma precipitação anual de 1.300 mm (Moreno, 1961).
O testemunho PM-RS-D01 foi coletado no dia 6 de julho de 2006, durante expedição de campo realizada pela equipe do Laboratório de Palinologia Marleni Marques Toigo (LPMMT) do Instituto de Geociências, em colaboração com o Centro de Estudo de Geologia Costeira e Oceânica (CECO) da Universidade Federal do Rio Grande do Sul (UFRGS). Através de percussão manual, um tubo de PVC com $6 \mathrm{~m}$ de comprimento e 75 $\mathrm{mm}$ de diâmetro foi introduzido até a profundidade de 4,87 m. 0 testemunho foi encaminhado ao Laboratório de Sedimentologia do CECO, onde foram processadas as etapas de abertura e registro fotográfico de suas características, via descrição expedita da sedimentologia, aspectos texturais, cor e presença/ausência de fragmentos orgânicos. As amostras para o estudo das diatomáceas foram extraídas observando-se intervalos regulares de 4,7 cm com o auxílio de uma seringa de 1 ml. As amostras foram nomeadas M1 (481,0 cm) a M89 $(64,8 \mathrm{~cm})$.

Oito amostras de $10 \mathrm{~cm}$ de amplitude foram submetidas aos processos de secagem, desagregação, quarteamento, separação de finos, peneiramento, ensaios de decantação, cálculo dos parâmetros estatísticos e análise dos aspectos morfoscópicos dos minerais presentes, necessários para a definição das litologias recuperadas, no Laboratório de Sedimentologia do CECO-UFRGS, seguindo a metodologia descrita em Krumbein \& Pettijohn (1938) e a classificação de Shepard (1954).

Com o intuito de se obter o balizamento geocronológico do intervalo estudado, três amostras (459,7 a $471,6 \mathrm{~cm} ; 383,9$ a $395,9 \mathrm{~cm} ; 211,6$ a $225,6 \mathrm{~cm}$ ) foram selecionadas e enviadas ao Laboratório BETA ANALYTIC INC, na Flórida, EUA, para datação pelo método do ${ }^{14} \mathrm{C}$.

Para a recuperação de microfósseis silicosos foi adotado o método "M5" conforme Abrantes et al. (2005), com modificações, substituindo-se o Calgon da técnica original por pirofosfato de sódio, utilizado para a dispersão prévia das argilas em $0,78 \mathrm{~cm}^{3}$ de sedimento, seguido de ácido clorídrico para dissolução dos carbonatos e peróxido de hidrogênio para oxidação da matéria orgânica. Todos os procedimentos foram executados no LPMMT, em béqueres de $250 \mathrm{ml}$ e a lavagem dos diferentes reagentes foi realizada através de sucessivas decantações, sem o auxílio de centrífuga para evitar a quebra e perda de frústulas mais delicadas. Os resíduos das amostras tratadas foram estocados em frascos de $50 \mathrm{ml}$ e depositados no Herbário Alarich Schulz (HAS) do Museu de Ciências Naturais, Fundação Zoobotânica do Rio Grande do Sul.

A partir de uma alíquota diluída do sedimento tratado de cada nível amostrado foram confeccionadas, no mínimo, três lâminas permanentes utilizando a resina Naphrax $(\mathrm{IR}=1,74)$ como meio de montagem. Em todo o processo foram usadas pipetas plásticas descartáveis, para evitar contaminação entre os níveis.

A observação dos táxons foi efetuada em aumento de mil vezes, em microscópio Olympus BX51, no LPMMT, microscópio Olympus BX51 no Laboratório de 
Micropaleontologia do Instituto de Geociências da Universidade de Tübingen e microscópio Olympus CX31 de uso particular (GH). Um maior detalhamento das estruturas dos espécimes foi obtido pela utilização de microscopia eletrônica de varredura na Universidade de Tübingen, bem como no Centro de Microscopia Eletrônica da UFRGS. Todos os morfotipos localizados nas lâminas foram fotografados e medidos, vindo a constituir guia de contagem e banco de dados para futuras publicações de caráter taxonômico.

A identificação das diatomáceas fundamentou-se nas obras de Hustedt (1927-1966), Krammer \& Lange-Bertalot (1986, 1988, 1991a,b), Round et al. (1990), Witkowski et al. (2000) e Metzeltin et al. (2005).

A quantificação das diferentes espécies foi processada a partir do cálculo da abundância relativa. Todos os indivíduos encontrados foram quantificados e computados até a obtenção de uma população representativa, determinada pelo método gráfico de estabilização da curva a partir da adição de espécies novas com o aumento do número de valvas consideradas (Pappas \& Stoermer, 1996), desde que uma eficiência mínima de 85\% fosse atingida com não menos do que 300 registros valvares. Para Battarbee et al. (2001), este número é suficiente para emprego de técnicas de alta resolução envolvendo muitas amostras e é utilizado como parâmetro para inúmeros estudos paleolimnológicos que abrangem a abundância relativa de diatomáceas como descritores paleoambientais (p. ex. Sterken et al., 2008). Valvas fragmentadas e de espécies de Aulacosei$r a$ Thwaites em vista valvar, não foram consideradas nas contagens pela impossibilidade de identificação taxonômica.

As unidades amostrais de cada segmento foram agrupadas em função de suas características bióticas previamente logaritimizadas $[\log (\mathrm{x})+1]$, adotando como medida de dissimilaridade a distância Euclidiana, e como critério de aglomeração o Método pela Variância Mínima (Método de Wards; Romesburg, 1984), considerado altamente eficiente para a formação de grupos (Valentin, 2000). A nitidez dos agrupamentos e suficiência amostral foi determinada pela verificação da significância estatística entre os grupos em distintos níveis de corte via teste de hipóteses por aleatorização e autoreamostragem (Pillar, 1994-2006). Em seguida, objetivando a verificação da variabilidade das principais espécies responsáveis pelo agrupamento, aplicou-se Análise de Componentes Principais (ACP) por variância e covariância conforme procedimentos descritos em McCune \& Mefford (1999). A matriz biótica foi submetida à Análise de Espécies Indicadoras (Dufrêne \& Legendre, 1997) visando estabelecer quais espécies destacadas pela ACP possuíam vínculos significativos com algum dos grupos formados. Correlações entre estas espécies foram avaliadas via aleatorização e autoreamostragem, através do cômputo do coeficiente de correlação entre variáveis, que foi testado a partir da hipótese de nulidade (Ho), de não associação entre os pares examinados em 1.000 iterações (Pillar, 2001).

Os procedimentos estatísticos foram implementados com a utilização dos pacotes estatísticos PC-ORD, versão 4.0 para Windows (McCune \& Mefford, 1999) e MULTIV 2.1.1 (Pillar, 1994-2006).

\section{Resultados}

Os resultados indicaram a existência de 116 unidades taxonômicas considerados táxons distintos em função de suas distinções morfométricas, 112 identificadas ao nível genérico e 61 em âmbito específico, distribuídasem 25 gêneros. A figura 2 apresenta o perfil estratigráfico do testemunho PM-RS-D01, baseando-se nas análises granulométricas, bem como o resultado das datações pelo método ${ }^{14} \mathrm{C}$.

A análise de agrupamento separou as unidades amostrais em três grupos nítidos confirmados pela avaliação de suficiência amostral e significância dos níveis de partição geradas em 1.000 iterações de aleatorização e autoreamostragem para cada tamanho de amostra (Figs. 3 e 4).

A Análise de Componentes Principais (ACP) resumiu 39,3\% da variabilidade dos dados abióticos em seus dois primeiros eixos, e $45,8 \%$ do total nos três componentes (Tab. 1), destacando como descritores mais importantes para explicar a variância os 17 táxons listados na tabela 2 e ilustrados na figura 5. A análise de espécies indicadoras (Dufrêne \& Legendre, 1997) confirmou as associações significativas destes táxons a determinado grupo oriundo da análise de agrupamento (Tab. 2). A tabela 3 apresenta a distribuição destas espécies indicadoras ao longo dos 68 níveis fossilíferos do testemunho PM-RS-D01.

Tabela 1. Resumo da Análise de Componentes Principais ( ${ }^{*}=$ Eixo significativo).

\begin{tabular}{ccccc}
\hline Eixo & Autovalor & \% de Variância & \% de Variância Acumulada & Linha de Quebra de Autovalor \\
\hline $1^{*}$ & 452,383 & 25,554 & 25,554 & 80,855 \\
$2^{*}$ & 243,118 & 13,733 & 39,287 & 65,724 \\
$3^{*}$ & 115,989 & 6,552 & 45,839 & 58,158 \\
\hline
\end{tabular}




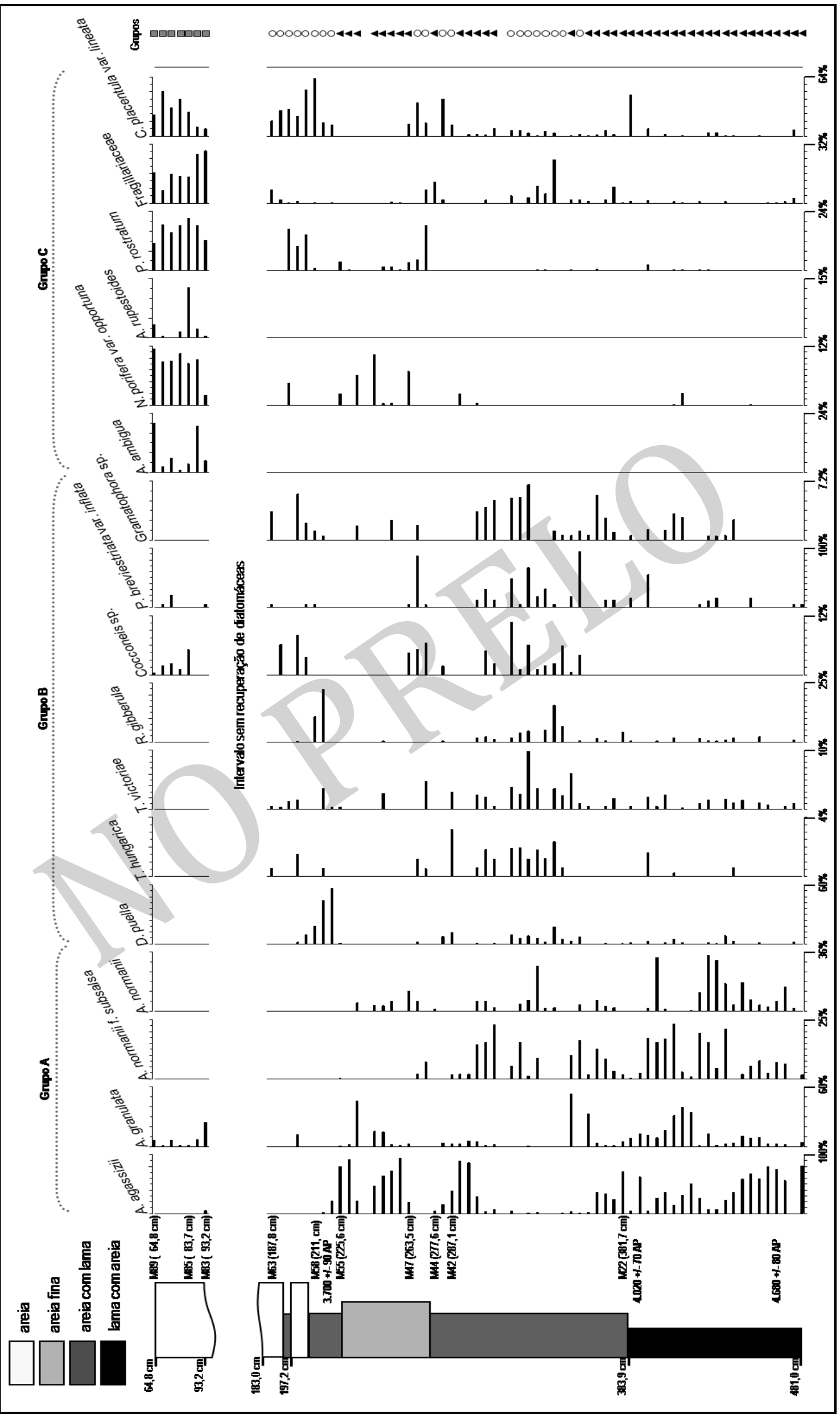

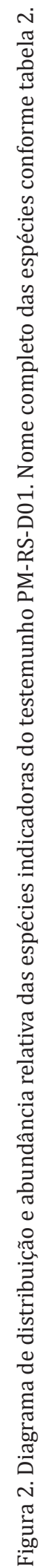




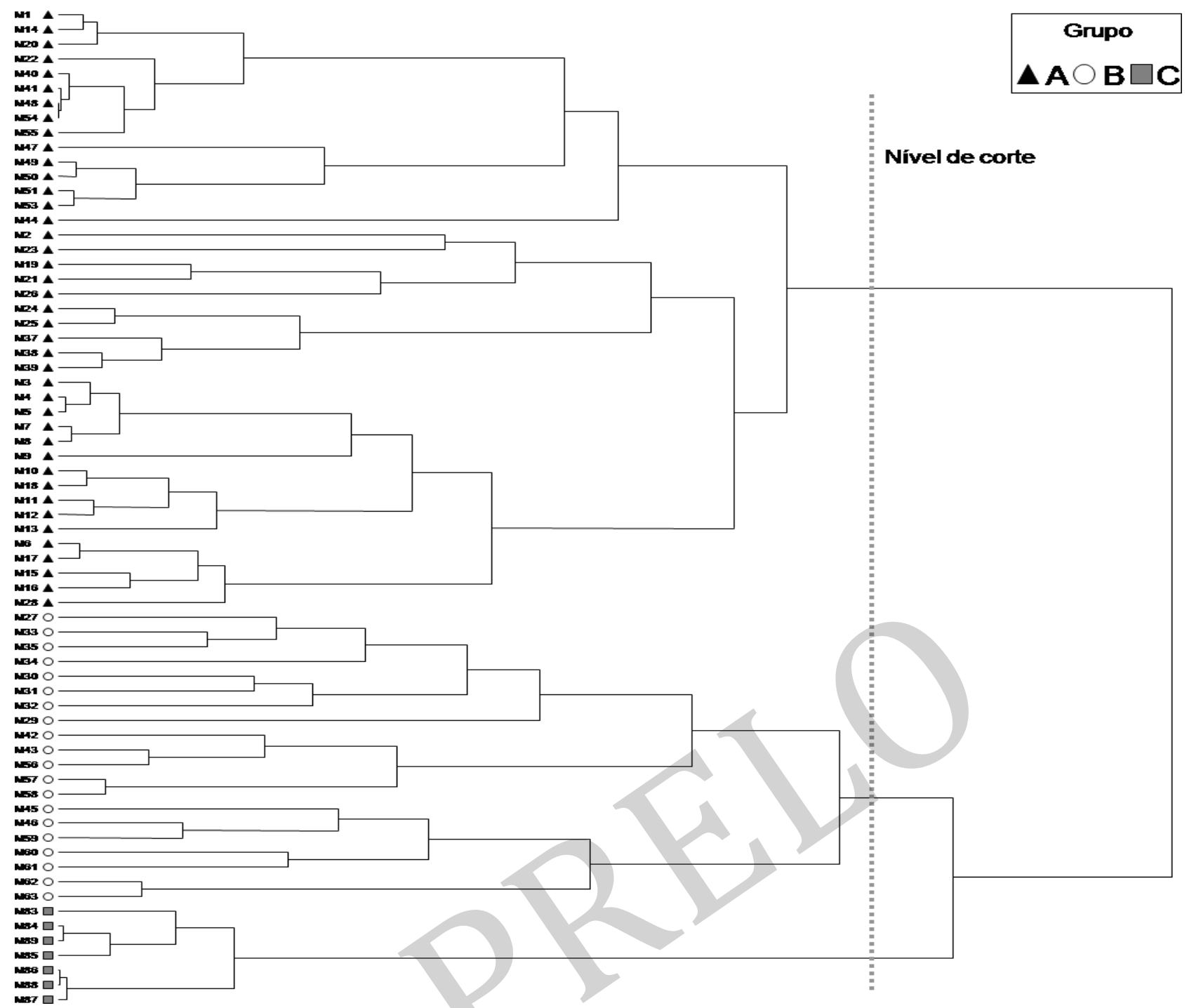

Figura 3. Análise de agrupamento (Distância Euclidiana; Método de Wards) das 68 amostras fossilíferas do testemunho PM-RS-D01.

Tabela 2. Correlação das espécies com os componentes principais 1, 2 e 3. Resumo da Análise de Espécies Indicadoras e Teste Monte Carlo com 1.000 iterações. $\mathrm{VI}=$ valor indicativo; $\mathrm{P}=$ probabilidade.

\begin{tabular}{|c|c|c|c|c|c|c|}
\hline \multirow[b]{2}{*}{ Espécies } & \multicolumn{3}{|c|}{ Componentes Principais } & \multicolumn{3}{|c|}{ Espécies Indicadoras } \\
\hline & 1 & 2 & 3 & Grupo & VI & $\mathbf{P}$ \\
\hline Aulacoseira cf. agassizii (Ostenf.) Simonsen (fig. 5a-d) & $-0,576$ & 0,190 & $-0,193$ & A & 87,5 & 0,001 \\
\hline Aulacoseira granulata (Ehrenberg) Simonsen (fig. 5g-i) & $-0,203$ & 0,274 & 0,288 & A & 55,8 & 0,020 \\
\hline Actinocyclus normanii f. subsalsa (Juhlin-Dannfelt) Hustedt (fig. $5 \mathrm{e}, \mathrm{f} ; \mathrm{l}, \mathrm{m}$ ) & $-0,211$ & $-0,282$ & 0,458 & A & 52,0 & 0,014 \\
\hline Actinocyclus normanii (Gregory) Hustedt (fig. 5ai, aj) & $-0,205$ & $-0,216$ & 0,407 & A & 50,6 & 0,018 \\
\hline Diploneis puella (Schumann) Cleve (fig. 5am-ap) & 0,063 & $-0,331$ & $-0,321$ & B & 76,5 & 0,001 \\
\hline Tryblionella hungarica (Grunow) D. G. Mann (fig. 5aq-at) & 0,036 & $-0,132$ & $-0,009$ & B & 55,9 & 0,001 \\
\hline Tryblionella victoriae Grunow (fig. $5 \mathrm{ak}$, al) & 0,004 & $-0,200$ & 0,020 & B & 53,4 & 0,009 \\
\hline Rhopalodia gibberula (Ehrenberg) O.F. Muller (fig. 5az, ba) & 0,021 & $-0,226$ & $-0,168$ & B & 46,9 & 0,026 \\
\hline Cocconeis sp. (fig. $5 \mathrm{q}, \mathrm{r}$ ) & 0,173 & $-0,165$ & 0,077 & B & 44,1 & 0,010 \\
\hline Pseudostaurosira brevistriata var. inflata (Pantocsek) B. Hartley (fig. 5ad-ah) & 0,054 & $-0,184$ & 0,175 & B & 38,5 & 0,079 \\
\hline Grammatophora sp. (fig. $5 \mathrm{ab}, \mathrm{ac}$ ) & 0,014 & $-0,195$ & 0,073 & B & 38,2 & 0,051 \\
\hline Aulacoseira ambigua (fig. 5bb-bd) & 0,125 & 0,190 & 0,151 & $\mathrm{C}$ & 100,0 & 0,001 \\
\hline Navicula porifera var. opportunna (Hustedt) Lange-Bertalot (fig. 5au-ay) & 0,125 & 0,282 & 0,161 & $\mathrm{C}$ & 89,2 & 0,001 \\
\hline Achnanthes rupestoides (fig. $5 \mathrm{n}-\mathrm{p}$ ) & 0,073 & 0,101 & 0,079 & $\mathrm{C}$ & 85,7 & 0,001 \\
\hline Planothidium rostratum (Oestrup) Lange-Bertalot (fig. $5 \mathrm{x}$-aa) & 0,277 & 0,246 & 0,220 & $\mathrm{C}$ & 81,1 & 0,001 \\
\hline $\begin{array}{l}\text { Fragilariaceae (fig } 5 \text { j,k; s-v) } \\
\text { Cocconeis placentula var. lineata (Ehrenberg) Van Heurck (fig. 5be-bg) }\end{array}$ & $\begin{array}{l}0,251 \\
0,444\end{array}$ & $\begin{array}{r}0,092 \\
-0,054\end{array}$ & $\begin{array}{l}0,211 \\
0,004\end{array}$ & $\begin{array}{l}\mathrm{C} \\
\mathrm{C}\end{array}$ & $\begin{array}{l}79,4 \\
55,5\end{array}$ & $\begin{array}{l}0,001 \\
0,013\end{array}$ \\
\hline
\end{tabular}




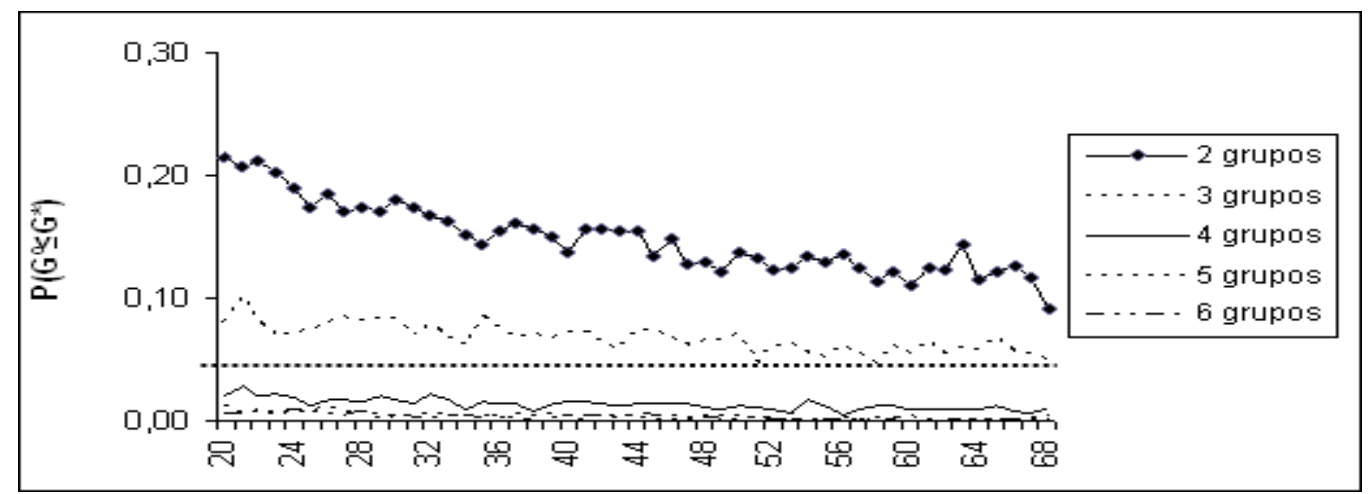

Figura 4. Avaliação da suficiência amostral e significância de níveis de partição da análise de agrupamento das 68 amostras fossilíferas do testemunho PM-RS-D01, através das probabilidades $P\left(G^{\circ} \leq G^{*}\right)$ geradas em 1.000 iterações de aleatorização e autoreamostragem para cada tamanho de amostra.

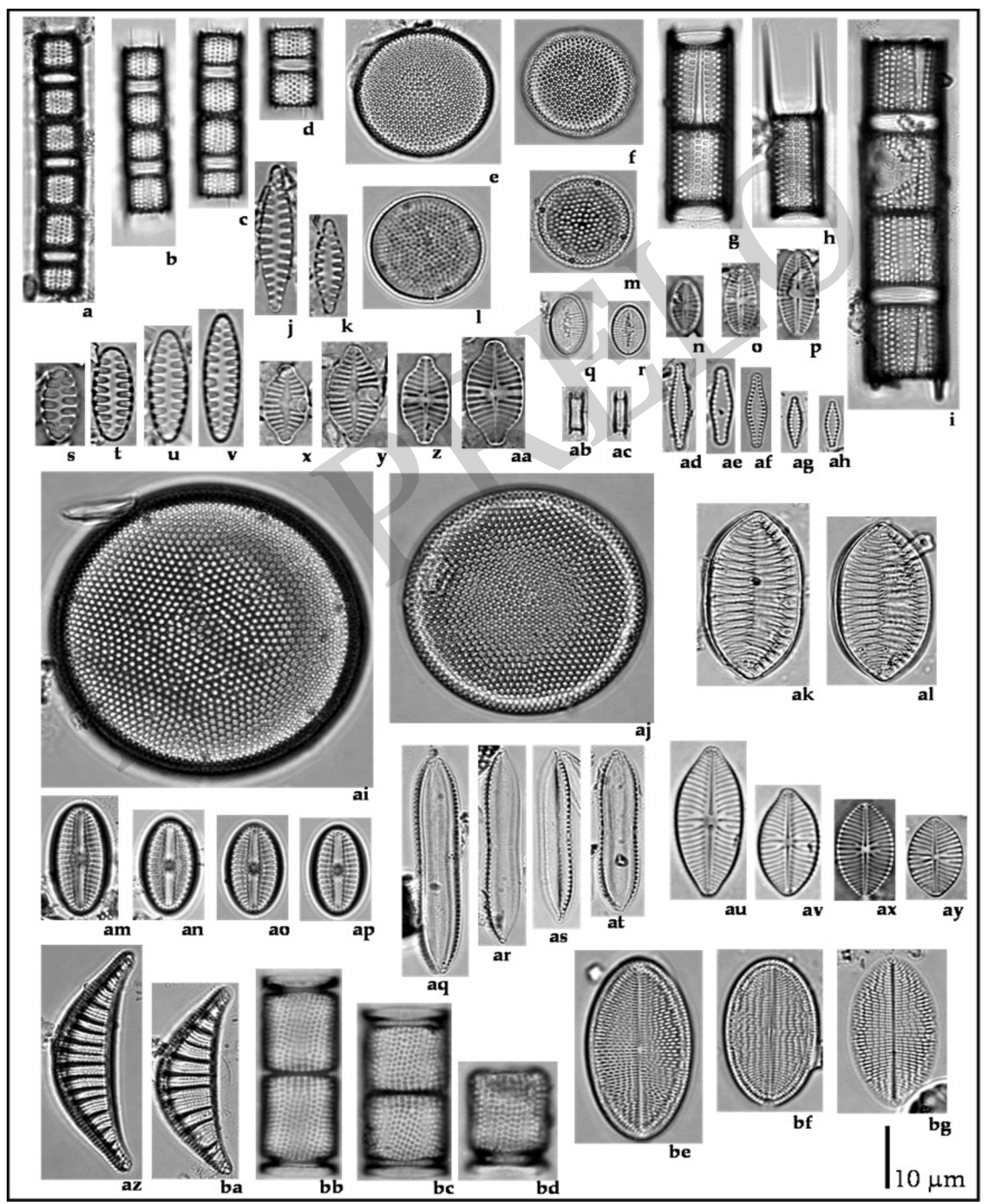

Figura 5. Espécies indicadoras do testemunho PM-RS-D01. (a-d) Aulacoseira cf. agassizii; (e,f; l,m) Actinocyclus normanii f. subsalsa; (gi) Aulacoseira granulata; (j,k) Staurosirella leptostauron var. dubia; (n-p) Achnanthes rupestoides; (q,r) Cocconeis sp.; (s-v) Staurosirella martyi; (x-aa) Planothidium rostratum; (ab, ac) Gramatophora sp.; (ad-ah) Pseudostaurosira bravistriata var. inflata; (ai, aj) Actinocyclus normanii; (ak, al) Tryblionella victoriae; (am-ap) Diploneis puella; (aq-at) Tryblionella hungarica; (au-ay) Navicula porifera var. opportuna; (az, ba) Rhopalodia gibberula; (bb-bd) Aulacoseira ambigua; (be-bg) Cocconeis placentula var. lineata. 


\begin{tabular}{|c|c|c|c|c|c|c|c|c|c|c|c|c|c|c|c|c|c|c|c|c|c|}
\hline 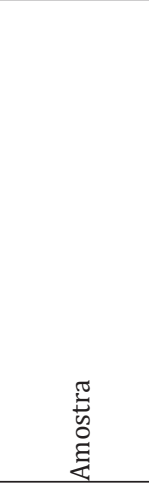 & 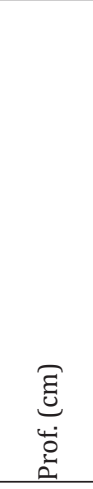 & ్ٌٍ & 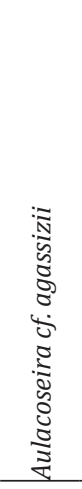 & 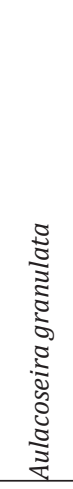 & 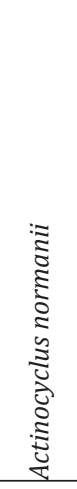 & 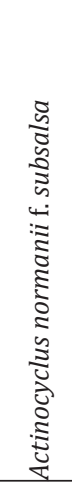 & 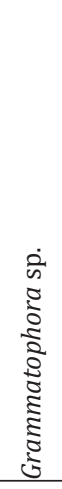 & 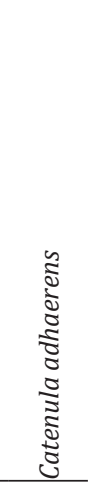 & 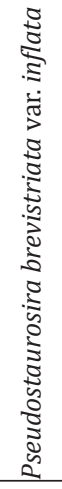 & 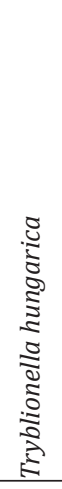 & 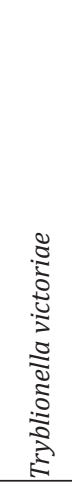 & 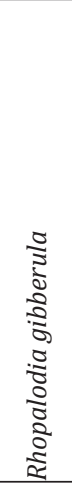 & 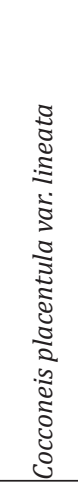 & $\begin{array}{l}\dot{0} \\
\tilde{w} \\
\tilde{\Xi} \\
\tilde{\delta} \\
\dot{U} \\
0\end{array}$ & $\begin{array}{l}\frac{0}{0} \\
\frac{0}{2} \\
\frac{2}{2} \\
\frac{2}{2} \\
\frac{0}{0} \\
\frac{a}{0}\end{array}$ & 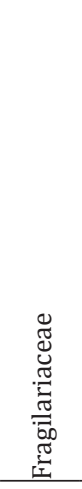 & 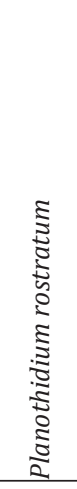 & 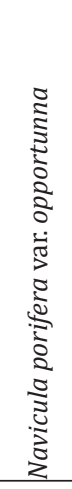 & 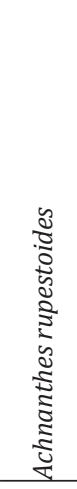 & 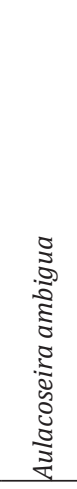 & 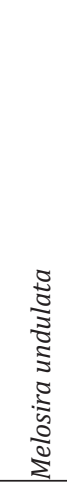 \\
\hline M89 & 64,8 & $\mathrm{C}$ & & 6,9 & & & & & & & & & 23,1 & 0,6 & & 16,8 & 11,6 & 11,6 & 3,5 & 2,2 & \\
\hline M88 & 63,5 & C & & 1,6 & & & & & 0,6 & & & & 49,7 & 1,9 & & 7,1 & 18,9 & 9,6 & 0,6 & 2,5 & 0,6 \\
\hline M87 & 74,3 & C & & 6,7 & & & & & 2,1 & & & & 31,4 & 2,4 & & 15,9 & 15,9 & 9,1 & & 6,8 & \\
\hline M86 & 78,9 & C & & 2,7 & & & & & & & & & 39,9 & 1,2 & & 14,8 & 18,6 & 1,7 & 1,8 & 1,2 & \\
\hline M85 & 83,7 & C & & 2,2 & & & & 1,8 & & & & & 26,5 & 5,2 & & 14,5 & 21,5 & 8,6 & 12,9 & 3,7 & 0,6 \\
\hline M84 & 88,4 & C & 1,2 & 7,3 & & & & 1,2 & & & & & 1,0 & & & 27,0 & 18,5 & 9,4 & 2,4 & 20,0 & 1,5 \\
\hline M83 & 93,2 & $\mathrm{C}$ & 6,3 & 24,8 & & & & 1,9 & 0,6 & & & & 8,5 & & & 28,5 & 12,5 & 2,2 & 0,6 & 5,2 & 10,0 \\
\hline M64 - M82 & & & & & & & & $(183$, & -97 & $9 \mathrm{~cm})$ & Inter & ralo se & m mic & ofós & eis sil & icosos & & & & & \\
\hline M63 & 187,8 & B & & & & & 3,6 & 0,6 & 0,6 & $0,6^{\prime}$ & 0,6 & & 17,7 & & & 7,8 & & & & & \\
\hline M62 & 192,5 & B & & & & & & 14,7 & & & 0,6 & & 28,3 & 6,2 & & 2,3 & & & & & \\
\hline M61 & 197,2 & B & & & & & & 7,2 & & & 1,5 & & 29,5 & & & 0,5 & 17,2 & 4,6 & & & \\
\hline M60 & 201,9 & B & & 12,9 & & & 5,7 & 13,1 & & 1,5 & 1,8 & 0,5 & 21,9 & 8,2 & 2,8 & 1,5 & 1,3 & & & & \\
\hline M59 & 206,7 & B & & & & & 2,9 & 5,7 & 0,6 & & & & 5,4 & 3,6 & 9,9 & & 14,9 & & & & \\
\hline M58 & 211,4 & B & & & & & 1,2 & 1,8 & 0,7 & & & 1,8 & 62,8 & & 18,6 & 0,7 & 1,2 & & & & \\
\hline M57 & 216,2 & B & 3,2 & & & & 0,6 & 0,6 & & 0,6 & 3,6 & 22,7 & 15,2 & & 45,3 & & & & & & \\
\hline M56 & 220,9 & B & 21,7 & 0,8 & & & & 3,7 & & & 0,5 & & 12,8 & & 57,5 & 0,5 & 0,5 & & & & \\
\hline M55 & 225,6 & A & 8,2 & 0,8 & & 0,5 & & 0,5 & & & 0,5 & & 0,5 & & 1,3 & & 3,7 & 2,5 & & & \\
\hline M54 & 230,3 & A & 92,4 & 2,8 & & & & 2,2 & & & & & 0,6 & & & & 0,6 & & & & \\
\hline M53 & 235,1 & A & 22,3 & 46,4 & 5,4 & & 1,8 & 7,1 & & & & & & & & & & 6,3 & & & \\
\hline M52 & 239,8 & & & & & & & & & Sen & a micr & fósse & is silic & Sos & & & & & & & \\
\hline M51 & 244,5 & A & 47,9 & 15,8 & 3,9 & & & 19,6 & & & & & & & & & & 1,4 & & & \\
\hline M50 & 249,3 & A & 64,9 & 15,1 & 3,7 & & & 7,7 & & & 2,9 & 0,6 & & & & & 2,0 & 0,6 & & & \\
\hline M49 & 254 & A & 73,2 & 2,5 & 6,5 & & 2,5 & 11,4 & & & & & & & & 0,9 & 1,8 & 0,6 & & & \\
\hline M48 & 258,7 & A & 95,0 & 1,9 & 0,6 & & & & & & & & & & 0,6 & 0,6 & 0,6 & & & & \\
\hline M47 & 263,5 & A & 2,8 & 3,2 & 12,4 & & & 11,6 & 0,5 & & & & 13,7 & 4,6 & & & 3,5 & 7,9 & & & \\
\hline M46 & 268,2 & B & & & 6,5 & 2,5 & 1,9 & 14,3 & 8,7 & 1,2 & & & 36,8 & 5,3 & 2,5 & & 4,7 & & & & \\
\hline M45 & 272,9 & B & & & & 7,4 & & 8,9 & 0,6 & 0,6 & 4,8 & & 14,5 & 6,5 & 0,6 & 7,7 & 18,8 & & & & \\
\hline M44 & 277,6 & $\mathbf{A}$ & 5,1 & 0,3 & 1,8 & & & 1,3 & & & & & & & 0,6 & 11,5 & & & & & \\
\hline M43 & 282,4 & B & 16,6 & 4,2 & & & & 4,2 & & & & 0,6 & 4,6 & 1,9 & 8,4 & 2,2 & & & & & \\
\hline M42 & 287,1 & B & 39,8 & 3,0 & & 1,9 & & & & 3,2 & 3,0 & & 12,7 & & 12,1 & & & & & & \\
\hline M41 & 291,8 & $\mathbf{A}$ & 89,1 & 3,3 & 0,6 & 2,1 & & 1,0 & & & & & & & & & & 2,4 & & & \\
\hline M40 & 296,6 & A & 87,0 & 6,5 & & 2,2 & & & & & & & 2,2 & & & & & & & & \\
\hline M39 & 301,3 & A & 29,7 & 5,6 & 6,3 & 14,6 & 3,5 & 11,8 & 1,3 & 0,6 & 2,5 & 1,9 & 2,2 & & 1,6 & & & 0,6 & & & \\
\hline M38 & 306,0 & A & 4,8 & 2,2 & 6,6 & 15,7 & 4,8 & 13,5 & 3,1 & 1,9 & 2,2 & 2,6 & 1,9 & 5,2 & 0,6 & 1,9 & & & & & \\
\hline M37 & 310,8 & A & 8,3 & 2,8 & 2,5 & 23,6 & 5,0 & 5,0 & 1,2 & 1,2 & 0,6 & 1,2 & 8,6 & 2,5 & 0,9 & & & & & & \\
\hline M36 & 315,5 & & & & & & & & & Sen & a micr & fósse & is silic & sos & & & & & & & \\
\hline M35 & 320,2 & B & 5,5 & & & 5,8 & 5,2 & 1,4 & 4,9 & 1,9 & 3,9 & 1,9 & 6,8 & 1,7 & 1,3 & 4,3 & & & & & \\
\hline M34 & 324,9 & B & 1,3 & 0,7 & 4,9 & 15,7 & 5,2 & 4,6 & 0,7 & 2,0 & 2,6 & 4,3 & 6,9 & 1,3 & 6,2 & & & & & & \\
\hline M33 & 329,7 & B & 1,9 & 1,2 & 7,1 & 1,5 & 6,8 & 2,5 & 6,8 & 1,2 & 10,0 & 5,0 & 3,7 & 6,2 & 9,3 & 3,5 & & & & & \\
\hline M32 & 334,4 & B & 3,3 & 0,7 & 27,7 & 9,1 & & & 1,8 & 1,8 & 3,6 & & 1,2 & 1,2 & 6,4 & 9,4 & 0,7 & & & & \\
\hline M31 & 339,1 & B & 0,9 & & 2,3 & & & & 3,2 & 1,3 & & 5,4 & 5,7 & 1,9 & 3,2 & 5,4 & 0,6 & & & & \\
\hline M30 & 343,9 & B & & & 2,5 & & 1,2 & & 0,6 & 2,5 & 3,6 & 15,7 & 4,2 & 2,5 & 18,7 & 23,8 & & & & & \\
\hline M29 & 348,6 & B & 2,2 & 0,6 & 0,6 & & 0,6 & 2,5 & & 0,6 & 2,5 & 6,5 & & 5,9 & 5,7 & & & & & & \\
\hline M28 & 353,3 & A & 4,3 & 53,4 & & 1,2 & 0,7 & 3,0 & 2,0 & & 6,2 & & 1,3 & 0,7 & 3,9 & 2,3 & 0,7 & & & & \\
\hline M27 & 358,1 & B & 2,8 & & 4,5 & 16,6 & 1,2 & 3,3 & 9,5 & & 1,2 & 0,6 & 2,4 & 4,2 & 8,1 & 2,4 & & & & & \\
\hline M26 & 362,8 & A & 2,9 & 33,0 & & 1,9 & 0,6 & 3,5 & & & 0,6 & & 1,3 & & & 1,3 & & & & & \\
\hline M25 & 367,5 & A & 35,9 & 3,9 & 6,9 & 12,7 & 5,6 & 9,2 & & & & 1,6 & 2,0 & & & & 1,0 & & & & \\
\hline M24 & 372,2 & $\mathbf{A}$ & 34,2 & 2,2 & 3,4 & 8,6 & 2,8 & 14,5 & 1,2 & & 0,6 & 0,6 & 6,5 & & 1,8 & 1,8 & & & & & \\
\hline M23 & 376,9 & A & 24,5 & 1,7 & 2,6 & 3,6 & 1,0 & 1,0 & 1,3 & & 2,0 & & 2,0 & & & 8,9 & & & & & \\
\hline M22 & 381,7 & A & 71,4 & 5,3 & & 2,0 & & 2,7 & & & & 4,3 & & & 1,0 & 0,7 & & & & & \\
\hline M21 & 386,4 & $\mathbf{A}$ & 4,9 & 9,2 & & 0,7 & 0,7 & 3,9 & 1,6 & & 0,7 & 0,7 & 45,6 & & 2,0 & 1,3 & & & & & \\
\hline M20 & 391,2 & A & 62,6 & 13,1 & & 2,6 & & 2,0 & & & & & & & & & & & & & \\
\hline M19 & 395,9 & A & 5,0 & 11,9 & 2,2 & 17,5 & 1,4 & 2,8 & 5,6 & 1,7 & 2,2 & & 8,3 & & 3,9 & 1,7 & 2,8 & & & & \\
\hline M18 & 400,6 & A & 27,4 & 9,4 & 33,2 & 15,6 & & & & & 0,7 & 0,7 & & & 0,7 & & & & & & \\
\hline M17 & 405,4 & A & 37,1 & 16,8 & 1,6 & 17,1 & 1,3 & 1,3 & & & 2,5 & & 2,2 & & 2,2 & & 0,3 & & & & \\
\hline M16 & 410,1 & A & 15,0 & 31,7 & & 23,4 & 3,3 & 0,6 & & 0,3 & & 3,0 & & & 5,7 & 1,2 & 0,6 & 0,3 & & & \\
\hline M15 & 417,8 & A & 32,5 & 39,4 & & 3,3 & 2,9 & & & & 0,3 & & 1,3 & & 2,2 & 0,6 & 0,6 & 2,6 & & & \\
\hline M14 & 419,5 & A & 51,5 & 34,8 & 1,0 & 1,2 & & & & & & & & & & & & & & & \\
\hline M13 & 424,3 & A & 27,6 & 1,8 & 11,8 & 19,4 & & 1,2 & 0,6 & & 1,2 & 1,8 & 0,6 & & & 1,2 & 0,6 & & & & \\
\hline M12 & 429,0 & A & 8,3 & 14,0 & 34,2 & 15,5 & 0,6 & 0,6 & 1,2 & & 1,8 & 0,6 & 4,2 & & 2,8 & & 0,6 & & & & \\
\hline M11 & 433,7 & $\mathbf{A}$ & 8,1 & 2,2 & 31,9 & 4,8 & 0,6 & & 1,7 & & & 0,6 & 4,5 & & 1,1 & & & & & & \\
\hline M10 & 438,5 & A & 23,9 & 3,3 & 17,3 & 21,2 & 0,7 & 1,2 & & & 1,8 & 1,2 & 1,2 & & 10,0 & 1,2 & & & & & \\
\hline M09 & 443,2 & A & 37,3 & 4,1 & 4,4 & & 2,5 & 3,2 & & 0,6 & 1,3 & 1,9 & 0,9 & & 3,5 & & & & & & \\
\hline M08 & 447,9 & A & 59,2 & 1,9 & 17,8 & 2,3 & & & & & 1,7 & & & & 0,6 & & & & & & \\
\hline M07 & 452,6 & A & 68,3 & 10,0 & 7,4 & 5,6 & & & 1,7 & & & & 0,3 & & 0,6 & & & 0,3 & & & \\
\hline M06 & 457,4 & A & 6,0 & 9,5 & 4,1 & 7,9 & & & & & 1,3 & 2,5 & 1,0 & & 1,9 & & & & & & \\
\hline M05 & 462,1 & $\mathbf{A}$ & 79,3 & 3,4 & 3,1 & 2,5 & & & & & 0,8 & & & & & 0,6 & & & & & \\
\hline M04 & 466,8 & A & 74,9 & 3,0 & 6,8 & 7,2 & & 0,6 & & & & & & & & 0,6 & & & & & \\
\hline M03 & 471,6 & $\mathbf{A}$ & 56,2 & 2,7 & 15,2 & 6,7 & & 1,8 & & & 0,7 & 0,3 & & & 0,7 & 1,2 & & & & & \\
\hline $\begin{array}{l}\text { M02 } \\
\text { M01 }\end{array}$ & $\begin{array}{l}476,3 \\
481,0\end{array}$ & $\stackrel{\mathbf{A}}{\mathbf{A}}$ & $\begin{array}{c}1,2 \\
81,8\end{array}$ & $\begin{array}{l}0,6 \\
4,6\end{array}$ & 2,4 & 2,2 & & 0,3 & $\begin{array}{l}0,6 \\
0,6\end{array}$ & & 1,2 & 1,2 & 7,5 & & 2,6 & $\begin{array}{l}2,9 \\
0,3\end{array}$ & & & & & \\
\hline
\end{tabular}


Por constituírem as espécies mais correlacionadas com o componente de maior explicabilidade, para Aulacoseria cf. agassizii e Cocconeis placentula var. lineata foram atribuídas a dicotomia primária dos níveis do testemunho PM-RS-D01, que confirmou as unidades do agrupamento A mais à esquerda da origem do eixo 1 (Figs. 6 e 7).

Apresentando correlação positiva com o eixo 2, Navicula porifera var. opportuna, Planothidium rostratum, Aulacoseira ambigua e Achnanthes rupestoides (sinônimo de Achnanthes hustedtii (Krasske) Reimer e transferida para Platessa hustedtii (Krasske) Lange-Bertalot) destacam-se como representativas dos paleoambientes que deram origem à deposição dos sedimentos que viriam a constituir os níveis de amostragem que compõem o grupo C (Tab. 3, Figs. 6 e 8). De forma oposta, projetando-se negativamente ao eixo 2, Diploneis puella, Rhopalodia gibberula, Tryblionella victoriae, Grammatophora sp., Pseudostaurosira brevistriata var. inflata, Tryblionella hungarica, conjuntamente a Cocco- neis sp., Cocconeis placentula var. lineata e Fragilariaceae, que se prolongam também sobre a esfera positiva do eixo 1, caracterizam o agrupamento B na interseção dos eixos 1 e 2 (Tab. 3, Figs. 6 e 8).

As duas espécies indicadoras do grupo A com maior destaque sobre o componente principal 1, Aulacoseira cf. agassizii e Actinocyclus normanii f. subsalsa, relacionam-se de maneira inversamente proporcional $(\lambda=-0,445, p=0,003)$, conforme revelado pela matriz de semelhança por correlação (Tab. 4). 0 cruzamento dos componentes principais 1 e 3 (Fig. 7) ressalta a contribuição da distribuição e abundância de Actinocyclus normanii para explicar a variabilidade dos dados, especialmente no que se refere ao contexto das amostras alocadas no grupo A. No entanto, é na figura que sintetiza as correlações das espécies com os eixos 2 e 3 (Fig. 8) que se percebe com maior clareza diferenças na composição específica dos níveis do grupo A, especialmente no que tange a Actinocyclus normanii f. subsalsa.

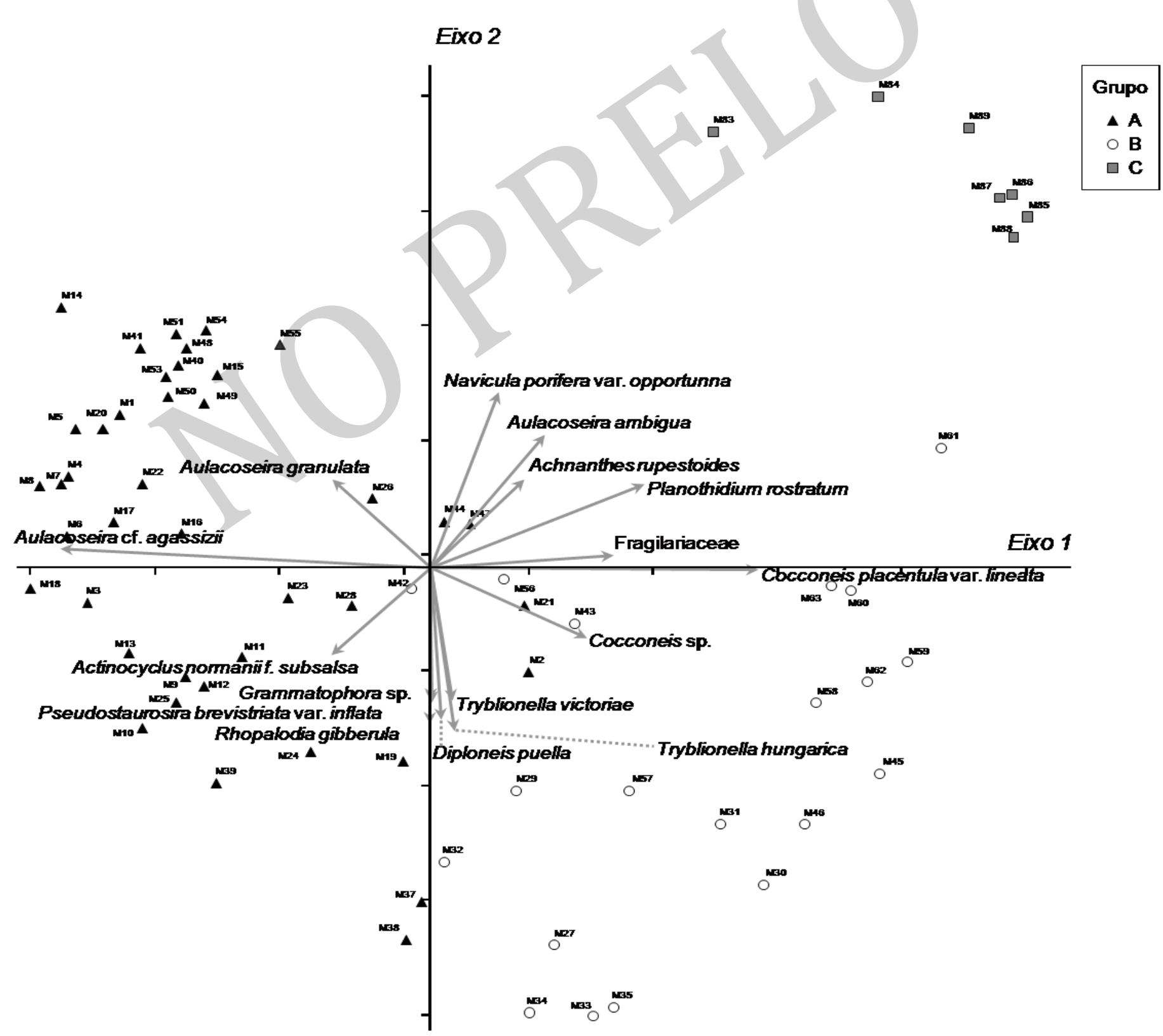

Figura 6. Resultado da Análise de Componentes Principais, evidenciando a relação das espécies descritoras com os agrupamentos A, B e C, nos eixos 1 e 2 . 


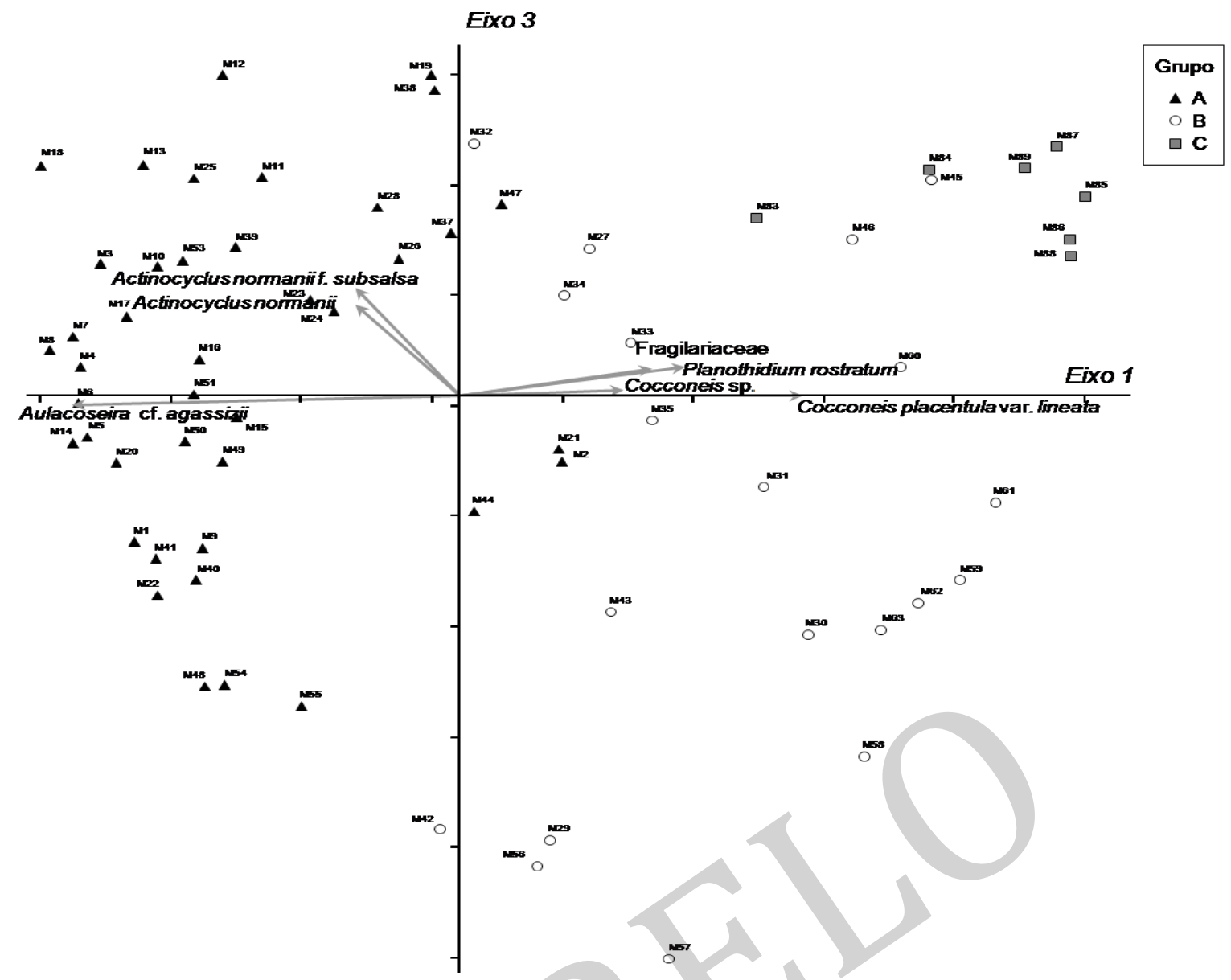

Figura 7. Resultado da Análise de Componentes Principais, evidenciando a relação das espécies descritoras com os agrupamentos A, B e C, nos eixos 1 e 3 .

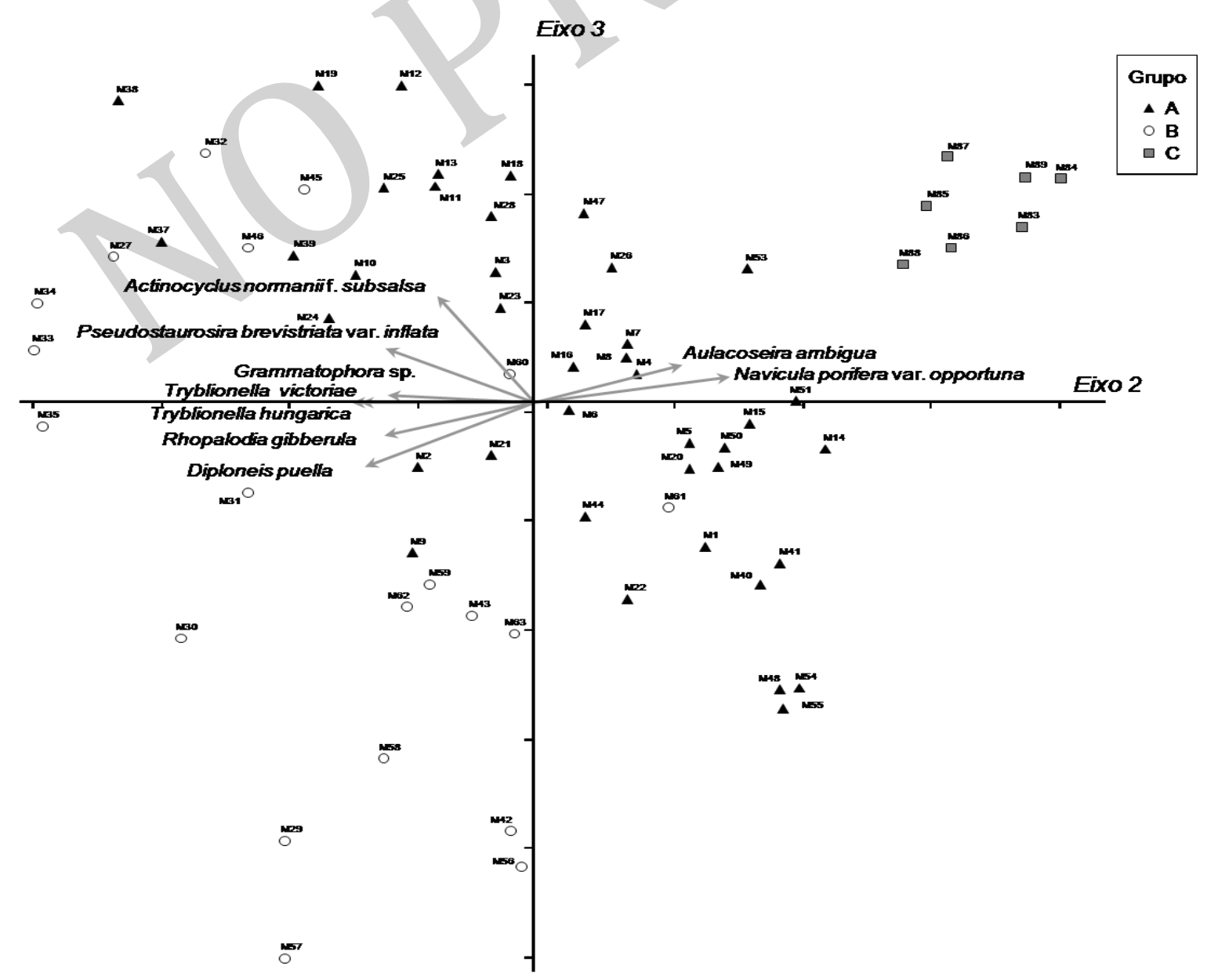

Figura 8. Resultado da Análise de Componentes Principais, evidenciando a relação das espécies descritoras com os agrupamentos A, B e C, nos eixos 2 e 3 . 
Tabela 4. Matriz de semelhança por correlação das espécies indicadoras do testemunho PM-RS-D01 no trecho correspondente as amostras do grupo A, abaixo da diagonal principal, e probabilidades correspondentes, acima desta.

\begin{tabular}{lrrrrc}
\hline Espécies & & $\mathbf{1}$ & $\mathbf{2}$ & $\mathbf{3}$ & $\mathbf{4}$ \\
\hline Actinocyclus normanii & $\mathbf{1}$ & & 0,054 & 0,253 & 0,099 \\
A. normanii f. subsalsa & $\mathbf{2}$ & 0,300 & & 0,948 & $\mathbf{0 , 0 0 3}$ \\
Aulacoseira granulata & $\mathbf{3}$ & $-0,183$ & 0,014 & & 0,096 \\
Aulacoseira cf. agassizii & $\mathbf{4}$ & $-0,261$ & $\mathbf{- 0 , 4 4 5}$ & $-0,274$ & \\
\hline
\end{tabular}

O levantamento da autoecologia dos táxons indicadores do testemunho PM-RS-D01 é referido na tabela 5. Durante as etapas de identificação e quantificação do material em microscopia óptica foi possível perceber a presença abundante de partículas silicosas em alguns níveis que, a primeira vista, não correspondiam a qualquer diatomácea conhecida (Fig. 5AB-AC). No entanto, tendo em vista sua repetência e constância morfométrica, foram computadas e assumiram destaque na análise de espécies indicadoras como representativas do grupo B (Tab. 2). Após verificação em microscopia eletrônica de varredura percebeu-se que estas unidades morfológicas eram constituídas por fragmentos celulares de alguma espécie de reduzida dimensão latitudinal com fileiras simples de aréolas, e valvocópula (banda intervalvar adjacente ao manto da valva) septada. As ilustrações do táxon foram encaminhadas para apreciação do Professor Emérito R. M. Crawford, que emitiu parecer onde comentou que estas estruturas poderiam ser atribuídas a alguma espécie do gênero Grammatophora.

\section{Discussão dos resultados}

4.1 Interpretação paleoambiental das amostras do grupo $A$

Os resultados obtidos para as amostras que compõem o grupo A parecem compatíveis com a existência de um paleosistema lagunar, submetido a oscilações entre períodos úmidos e secos, se analisados tomando como parâmetro de extrapolação, corpos aquosos com características lagunares atualmente existentes na região, como a Laguna de Tramandaí e a Laguna dos Patos. Na primeira, conforme Tomazelli \& Villwock (1991), as marés ocasionam, durante a preamar, a ingressão de uma cunha salina cuja capacidade de penetração determina a variação de salinidade. Os maiores graus de salinização da laguna são atingidos quando a maré alta atua conjuntamente a períodos de estiagem no continente.

Atualmente, a escarpa da Serra Geral atua como uma barreira natural à umidade que vem do oceano em direção ao continente (Hasenack \& Ferraro, 1989). Em função disto, a precipitação média na cidade de Maquiné (Fig. 1) é de $1.715 \mathrm{~mm}$, sensivelmente mais elevada que a taxa pluviométrica média do restante da planície costeira, que se situa em torno de $1.400 \mathrm{~mm}$ (Tomazelli \& Villwock, 1991). No passado, os volumes de água doce advindos de chuvas expressivas na região certamente também eram drenados para a planície costeira pelos rios Maquiné e Três Forquilhas (Fig. 1), diluindo as águas da paleolaguna, ou paleolagunas, ali existentes, atenuando, por consequência, sua salinidade.

A Laguna dos Patos drena uma bacia hidrográfica de aproximadamente $140.000 \mathrm{~km}^{2}$. A penetração da água do mar pelo canal de comunicação com o Oceano Atlântico nos períodos de menor aporte hídrico de seus tributários é controlada pela ação eólica que a dirige para dentro (ventos sudoeste) ou para fora (ventos nordeste) da laguna (Costa et al., 1988; Odebrecht et al., 2005).

Odebrecht et al. (2005) registraram entre dezembro de 1987 e novembro de 1988 para a região norte da laguna, e por conseguinte mais afastada da comunicação com o mar, diatomáceas de água doce do gênero Aulacoseira como principais componentes da biomassa fitoplanctônica. Torgan et al. (2006) demonstraram as associações fitoplanctônicas na laguna ao longo do eixo norte-sul no referido período. Estas se compuseram, no que tange às diatomáceas, essencialmente de representantes de Aulacoseira, Cyclotella (Kützing) Brébisson, Chaetoceros Ehrenberg e Skeletonema Greville. Os autores descreveram ainda um padrão de distribuição que, entre dezembro e março, período de clima mais úmido da pesquisa, nas áreas norte, central e sul, correspondem a associações respectivamente dulciaqüícolas, salobras e salobro-marinhas. Logo após houve o estabelecimento de clima seco, que impossibilitou a definição de grupos constituídos por espécies de água doce.

Assim, as unidades amostrais do grupo A com predomínio de Aulacoseira cf. agazzisii, cuja abundância em estudos paleolimnológicos tem sido atribuída ao declínio da influência marinha sobre ambientes lóticos costeiros (p.ex. Round et al., 1990; García-Rodriguez \& Witkowski, 2003; Stoermer \& Julius, 2003; Fluin et al., 2007), indicam que estas foram depositadas sob condições de baixa salinidade. Nestes momentos a influência da água doce, fruto de períodos de clima mais úmido e com fortes precipitações, escoada pelos rios Maquiné e Três Forquilhas até a planície costeira, suplantava, em intensidade, o afluxo das massas salinas provenientes do oceano (Figs. 1 e 2).

Neste sentido, García-Rodriguez \& Witkowski (2003) explicaram a existência de um pico de dominância de uma espécie de Aulacoseira [Aulacoseira granulata (Ehrenberg) Simonsen] como indicativo de copiosa precipitação episódica sobre a paleolaguna, onde atualmente se localiza a Laguna Rocha, no sul do Uruguai. Para Fluin et al. (2007), a abundância de Aulacoseira [Aulacoseira granulata] nos testemunhos de um lago raso no sul da Austrália, foi atribuída a um expressivo aporte de água doce do rio que desembocava no sistema devido ao aumento da pluviosidade. 
Esta hipótese de sucessão de períodos com regimes pluviométricos distintos encontra respaldo em Mayewski et al. (2004), que apresentaram evidências de modificações climáticas em escala global referentes a períodos úmidos e secos, no intervalo de 4.200 a 3.800 anos AP para o Holoceno, o qual inclui segmento composto pelas amostras do grupo A no testemunho PM-RS-D01.

Para a PCNRS, a partir de estudo palinológico em testemunho obtido no município de Terra de Areia (Fig. 1), Neves \& Lorscheitter (1995a) sugeriram um acentuado aumento de temperatura e precipitações na região por volta de $4.120 \pm 90$ anos AP, quando iniciou o desenvolvimento da floresta tropical na região.

Em estudo realizado a partir da análise de amostras oriundas de um testemunho localizado no Vale do rio Maquiné, RS, Medeanic et al. (2000a) e Marques-Toigo et al. (2002) referem-se a um estágio transgressivo com indicação de frequentes oscilações climáticas. Segundo os autores, pequenos períodos de aridez causaram o declínio de áreas florestais e de pântanos de água doce, com incremento das zonas de campo.

Outra interpretação muito aventada para elucidar as causas de alterações de salinidade em corpos aquáticos costeiros, cuja gênese tenha se iniciado no Holoceno, diz respeito às mudanças relativas do nível do mar (Martin \& Suguio, 1992; Angulo \& Lessa, 1997; Angulo et al., 1999; Lessa et al., 2000). A presença expressiva de Actinocyclus normanii e sua forma Actinocyclus normanii f. subsalsa entre $481 \mathrm{~cm}$ e $383,9 \mathrm{~cm}$, bem como, a manutenção da fácies lamosa no trecho, sugerem que alterações no nível relativo do mar não foram o principal fator responsável pelas oscilações de salinidade no Sistema Pinguela-Palmital-Malvas no intervalo de $4.680 \pm 80$ AP a $4.020 \pm 70$ AP (Fig. 2).

\subsection{Interpretação paleoambiental das amostras do gru- po $B$}

O incremento das espécies indicadoras do grupo B, essencialmente perifíticas e/ou salobras (Tab. 5), e a transição para sedimentos arenosos com lama após $4.020 \pm 70$ anos AP (Fig. 2), indicam redução de concentração salina e rebaixamento do nível lagunar provavelmente associado à submergência costeira relacionada com o máximo transgressivo que, entre 4.000 e 3.900 anos AP, situou o nível relativo do mar a uma condição ligeiramente abaixo do atual (Martin \& Suguio, 1992).

A presença de Pseudopodosira echinus (Frenguelli) Metzeltin et al. (Fig. 9), detectada em exame qualitativo após a quantificação, aos 381,7 cm (M22) corrobora a hipótese de mudança para uma fase de redução da coluna d'água em função do recuo do nível do mar.

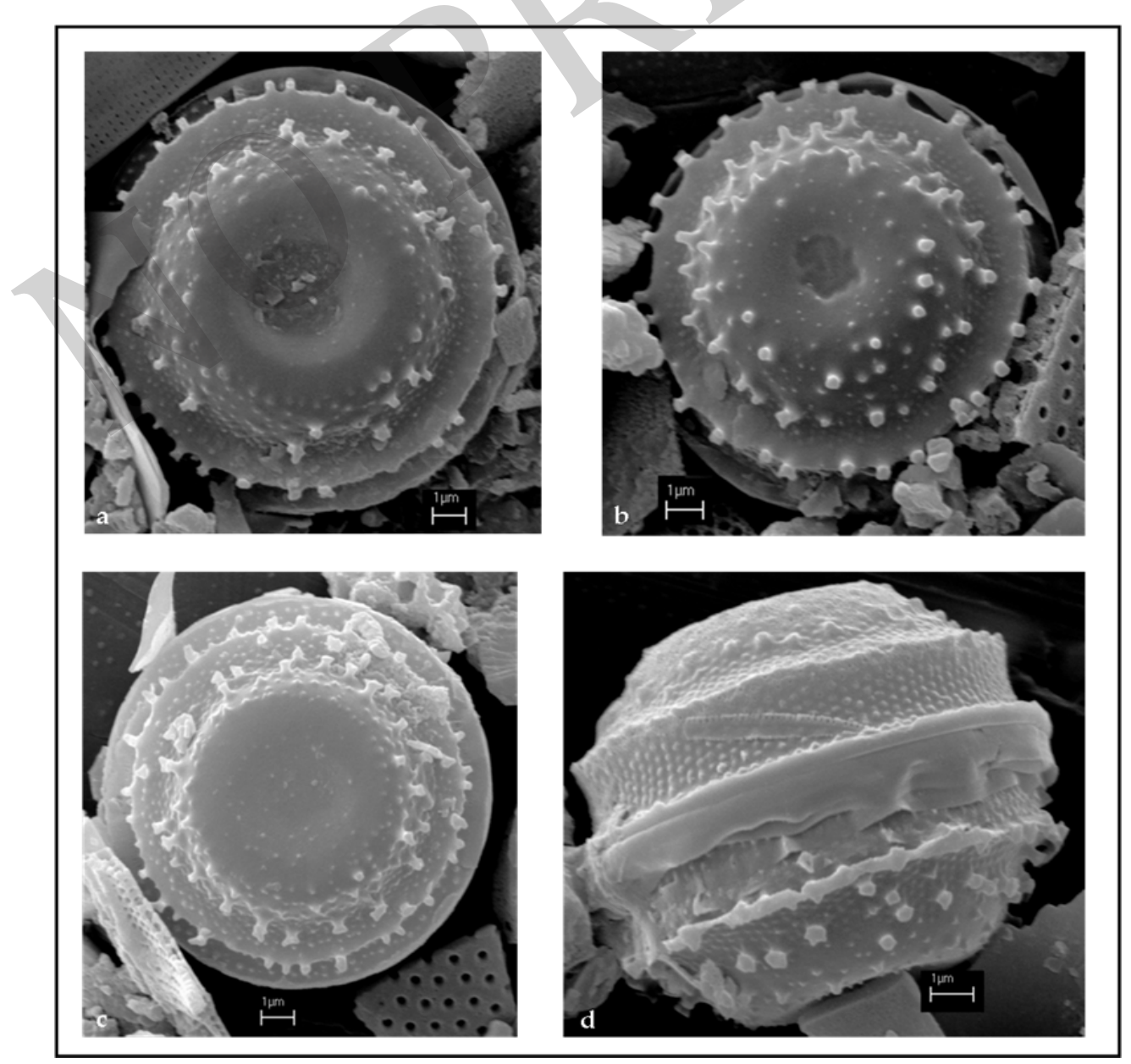

Figura 9. Pseudopodosira echinus em microscopia eletrônica de varredura. (a, b, c) vista valvar; (d) vista pleural. 
Tabela 5. Táxons indicadoras do testemunho PM-RS-D01, sua ecologia, grupo e paleoambiente indicativo.

\begin{tabular}{|c|c|c|c|}
\hline Espécies & Ecologia & Grupo & Paleoambiente \\
\hline Aulacoseira cf. agassizii & $\begin{array}{l}\text { Meroplanctônica dulciaqüícola, de águas rasas ou profundas e túrbidas (Gasse, } \\
\text { 1986; Nave et al., 2001; Chalié \& Gasse, 2002; Legesse et al., 2002). }\end{array}$ & \multirow{3}{*}{ A } & \multirow[b]{2}{*}{$\begin{array}{l}\text { Laguna em momento } \\
\text { de maior aporte de } \\
\text { água doce. }\end{array}$} \\
\hline Aulacoseira granulata & $\begin{array}{l}\text { Espécies deste gênero são meroplanctônicas e dulciaqüícolas, cuja abundância } \\
\text { relaciona-se ao declínio da influência marinha sobre ambientes lóticos } \\
\text { costeiros (e.g. Round et al., 1990; García-Rodriguez \& Witkowski, 2003; } \\
\text { Stoermer \& Julius, 2003; Fluin et al., 2007) }\end{array}$ & & \\
\hline $\begin{array}{l}\text { Actynocyclus normanii f. subsalsa } \\
\text { Actinocyclus normanii }\end{array}$ & $\begin{array}{l}\text { Actinocyclus normanii tem sido registrada para águas marinhas e salobras } \\
\text { (Brockmann, 1914) enquanto Actinocyclus normanii f. subsalsa é referida para } \\
\text { ecossistemas continentais salobros (Hasle, 1977; Torgan, 1997) }\end{array}$ & & Laguna. \\
\hline Diploneis puella & $\begin{array}{l}\text { Planctônica, alcaliófila, mesotrófica e de ambientes levemente salobros } \\
\text { (Patrick \& Reimer, 1975; Torgan \& Biancamano, 1991; Van Dam et al., 1994). }\end{array}$ & \multirow{7}{*}{ B } & \multirow{7}{*}{$\begin{array}{l}\text { Margem de } \\
\text { ambiente lagunar. }\end{array}$} \\
\hline Tryblionella hungarica & $\begin{array}{l}\text { Tryblionella é um gênero epipélico, comum em ambientes salobros e marinhos, } \\
\text { que pode também ocorrer em água doce com elevada condutividade (Round } \\
\text { et al., 1990; Lowe, 2003). }\end{array}$ & & \\
\hline Tryblionella victoriae & Espécie ticoplanctônica, mesohalóbia (Moro \& Fürstenberger, 1997). & & \\
\hline Rhopalodia gibberula & Espécie epifítica de águas salobras (Moro \& Fürstenberger, 1997). & & \\
\hline Cocconeis sp. & $\begin{array}{l}\text { Gênero encontrado desde água doce até ambientes marinhos, vivendo sobre } \\
\text { substratos rí́idos onde suas células vivem aderidas pela mucilagem expelida } \\
\text { pela rafe (Round et al., 1990; Ludwig \& Bigunas, 2006). }\end{array}$ & & \\
\hline Pseudostaurosira brevistriata var. inflata & $\begin{array}{l}\text { Florin (1970) destaca Pseudostaurosira brevistriata var. inflata como táxon } \\
\text { indiferente à salinidade, associado ao perifiton das margens de lagos pouco } \\
\text { profundos. }\end{array}$ & & \\
\hline Grammatophora sp. & $\begin{array}{l}\text { Gênero confinado ao litoral marinho onde estão aderidas a plantas e rochas } \\
\text { (Round et al., 1990). }\end{array}$ & & \\
\hline Aulacoseira ambigua & Ver Aulacoseira granulata. & \multirow{6}{*}{$\mathrm{C}$} & \multirow{6}{*}{$\begin{array}{l}\text { Margem de lagoa } \\
\text { costeira. }\end{array}$} \\
\hline Navicula porifera var. opportunna & $\begin{array}{l}\text { Espécie de água doce, oligosapróbica típica de lagos com baixo conteúdo } \\
\text { eletrolítico (Hustedt, 1961-1966; Krammer \& Lange-Bertalot, 1988; Hartley, } \\
\text { 1996). }\end{array}$ & & \\
\hline Achnanthes rupestoides & $\begin{array}{l}\text { Comum nas regiões pouco profundas de rios e lagos onde vive aderida sobre } \\
\text { plantas ou rochas em ambiente alcalino com concentração eletrolítica baixa ou } \\
\text { moderada (Krammer \& Lange-Bertalot, 1991b) }\end{array}$ & & \\
\hline Planothidium rostratum & $\begin{array}{l}\text { Planothidium engloba táxons dulciaqüícolas anteriormente atribuídos a } \\
\text { Achnanthes (Ludwig \& Bigunas., 2006), que crescem aderidos, via face valvar, a } \\
\text { substratos rígidos (Kingston, 2003). }\end{array}$ & & \\
\hline Fragilariaceae (Staurosirella) & $\begin{array}{l}\text { Staurosirella Williams \& Round é elemento comum da flora de águas doces e } \\
\text { rasas de ambientes lóticos e lênticos (Kingston, 2003). }\end{array}$ & & \\
\hline Cocconeis placentula var. lineata & $\begin{array}{l}\text { Espécie epifítica de água doce amplamente distribuída, algumas vezes } \\
\text { encontrada em águas levemente salobras (Patrick \& Reimer, 1966). }\end{array}$ & & \\
\hline
\end{tabular}

Pseudopodosira echinus não foi destacada pelos procedimentos estatísticos, por ter sido confundida com vistas valvares de Aulacoseira, não computadas conforme critério estabelecido. P. echinus e seu sinônimo Pseudopodosira kosugii Tanimura \& Sato é uma indicadora confiável de alterações do nível relativo do mar, atingindo máxima abundância na fase final de eventos transgressivos, de acordo com Tanimura \& Sato (1997) e García-Rodriguez \& Witkowski (2003).

Em M42 (287,1 cm) e M43 $(282,4 \mathrm{~cm})$, ocorre um acentuado declínio de Aulacoseira cf. agassizii seguido do predomínio acentuado de Cyclotella choctawhatcheeana Prasad (45,3\%) em M44 (277,6 cm), sugerindo o registro de um pulso de salinização do sistema (Tab. 3).

Cyclotella choctawhatcheeana (Fig. 10) foi originalmente descrita para a Baía Choctawhatchee, no México, por Prasad et al. (1990), sendo que, na maioria dos estudos paleolimnológicos anteriores, era referida como Cyclotella caspia Grunow (Melo et al., 2006). Hasle (1962) registrou esta espécie como muito abundante em fiordes e baías na Dinamarca e Noruega, em águas de 15-25\%, mas também presente em áreas com até
38 \%o. Sullivan (1978) reportou o táxon na comunidade edáfica de um pântano salgado no Mississipi, EUA.

Cyclotella choctawhatcheeana foi registrada pela primeira vez no Brasil no plâncton da Laguna Imboassica, estado do Rio de Janeiro. Trata-se de um pequeno $\left(3,3 \mathrm{~km}^{2}\right)$ e raso (profundidade média de $1,1 \mathrm{~m}$ ) sistema salobro sujeito a invasões de águas marinhas em função de aberturas artificiais da barra arenosa que separa a lagoa do oceano Atlântico. Devido a esta singularidade e ao despejo de esgoto doméstico em suas águas, a Laguna Imboassica apresenta uma grande variabilidade em termos de salinidade ( $>1$ a $35 \%$ ) e estado trófico (de condições oligotróficas a hipereutróficas) (Melo et al., 2006). Ainda, estes autores demonstraram que $C$. choctawhatcheeana atingiu seu desenvolvimento máximo em condições mesohalinas e mesoeutróficas. 0 táxon foi registrado em uma ampla faixa de salinidade, porém a densidade da população decresceu significativamente quando a concentração salina despencou para cerca de $3 \%$.

Logo após, entre M45 $(272,9 \mathrm{~cm})$ e M47 (263,5cm) ocorre o incremento de Cocconeis placentula var. linea- 


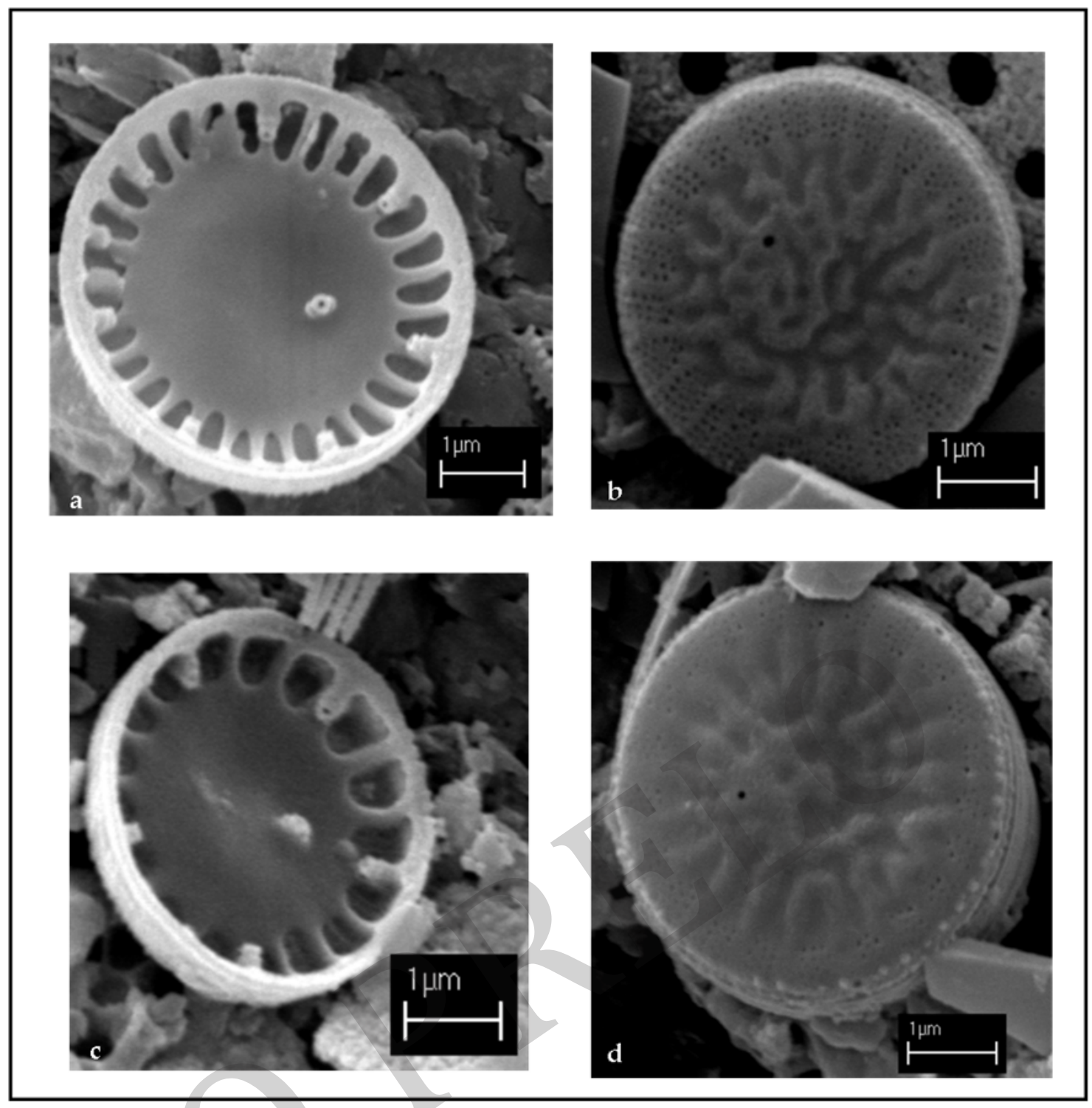

Figura 10. Cyclotella choctawhatcheeana, espécie abundante do nível M44 (277,6 cm) em microscopia eletrônica de varredura. (a,c) vista interna; (b,d) vista externa.

ta, o que, em primeira análise, sugere uma maior dessalinização do sistema. No entanto, estes níveis apresentam expressivas concentrações de Catenula adhaerens Mereschkowsky (Tab. 3). Este táxon foi referido por Hustedt (1957) e Simonsen (1962) como eurialino mesohalóbio, encontrado principalmente em águas salobras. A espécie foi amplamente distribuída na parte oeste do salobro mar Báltico (Simonsen, 1962; Pankow, 1976) e comumente encontrada no epipsamon da costa oeste sueca (Sundbäck \& Medlin, 1986). Assim, sua ocorrência nestas amostras indica a manutenção da influência marinha em um quadro de rebaixamento da coluna d'água.

Entre M48 (258,7 cm) e M55 (225,6 cm) o retorno do predomínio de Aulacoseira cf. agassizii, e o declínio de espécies perifíticas (Fig. 2, tab. 3) apontam para a queda da ascendência do ambiente oceânico durante a sedimentação destes níveis com provável incremento de precipitações na área em decorrência de novo período úmido.

O apogeu de Diploneis puella nas unidades M56
$(220,9 \mathrm{~cm})$ e M57 (216,2 cm) em um trecho de retorno à granulação correspondente à areia com lama indica elevação do nível d'água concomitante ao aumento da salinização do ambiente associadas à elevação do nível do mar, referida para a costa do Brasil em 3.600 anos AP (Martin \& Suguio,1992).

De M58 (211,4 cm) a M63 (187,8 cm) o declínio do táxon planctônico e salobro $D$. puella e substituição pela espécie epifítica de água doce Cocconeis placentula var. lineata, sugere novo rebaixamento do nível relativo do mar, cujo ápice teria ocorrido, de acordo com o modelo para a costa do Brasil, a cerca de 2.800-2.700 anos AP (Martin \& Suguio, 1992).

4.3 Interpretação paleoambiental do trecho do testemunho sem recuperação de fósseis silicosos $(183,0 \mathrm{~cm}$ a $93,2 \mathrm{~cm})$

Tendo em vista o fato da estação de coleta do testemunho PM-RS-D01 estar localizada onde no presente se estabeleceu um pontal arenoso (Fig. 1), a maior di- 
mensão dos grãos (Fig. 2) e a presença de raízes carbonizadas neste trecho, é plausível supor que este intervalo corresponda a um período de culminânica de retrocesso do nível d'água, onde o fundo da laguna neste ponto constituiu solo do pontal em um ambiente de comunicação mais restritiva com o oceano.

\subsection{Interpretação paleoambiental das amostras do gru- po $C$}

Após um longo trecho sem registro de fósseis silicosos, os sete níveis finais revelaram 22 táxons entre as amostras M83 (93,2 cm) e M89 (64,8 cm).

Destacam-se neste intervalo as espécies indicadoras representantes dos gêneros Achnanthes Bory, Aulacoseira, Cocconeis Ehrenberg, Navicula Bory e Planothidium Round \& Bukhtiyarova (Fig. 2). Também se sobressaíram táxons pertencentes à família Fragillariaceae (Fig. 2). Esta unidade taxonômica refere-se aqui a duas diatomáceas consideradas inicialmente variações morfológicas de uma mesma espécie em diferentes estágios de desenvolvimento: Staurosirella leptostauron var. dubia (Grunow) Bukhtiyarova (Fig. 5JK) e Staurosirella martyi (Héribaud) Morales \& Monoylov (Fig. 5SV).

O estabelecimento do predomínio de táxons perifíticos, dulciaqüícolas ou tolerantes a concentrações muito restritas de salinidade entre M83 $(93,2 \mathrm{~cm})$ e M89 $(64,8 \mathrm{~cm})$ apontam para a elevação da coluna d'água em decorrência da transgressão marinha holocena que, conforme registrado por Lorscheiter \& Dillenburg (1988) na Laguna de Tramandaí, teria ocorrido há 1.800 anos AP. 0 incremento da salinidade que acompanhou este fenômeno foi percebido pela presença de Catenula adhaerens e Melosira undulata (Ehrenberg) Kützing nas amostras M83 $(93,2 \mathrm{~cm})$, M84 $(88,4$ $\mathrm{cm})$ e M85 $(83,7 \mathrm{~cm})$.

A ausência de registro desta transgressão na Lagoa dos Quadros pode ser atribuída a uma segmentação mais recente dos corpos lagunares situados mais próximos à Laguna de Tramandaí (Meyer et al., 2005). Corroborando esta hipótese, o nível datado por Meyer et al. (2005) em $4.870 \pm 40$ anos A.P., situa-se no contexto de um sistema lagunar em fase regressiva onde predomina granulação arenosa. Já para o sistema Pinguela-Palmital-Malvas, no mesmo período, o sítio estudado encontra-se disposto em área com característica francamente lagunar, onde ainda é expressiva a influência oceânica.

A similaridade do trecho final do testemunho com as condições hidroquímicas atuais nos sistemas lênticos da região é corroborada pelo incremento de $\mathrm{Au}$ lacoseira ambigua (Grunow) Simonsen, espécie mais abundante entre as algas fitoplanctônicas em lagoas da PCNRS conforme Salomoni \& Schwarzbold (2004).

\section{Conclusões}

O testemunho PM-RS-D01 revelou a presença de diatomáceas fósseis com elevado grau de preservação. A manutenção das principais características morfológicas dos táxons possibilitou o reconhecimento de seus componentes em nível específico, indicando que os resultados extraídos não foram influenciados por problemas relativos ao grau de comprometimento das valvas.

As alterações paleobióticas detectadas refletiram essencialmente oscilações de habitats decorrentes de fatores climáticos e eustáticos que marcam de maneira evidente duas fases distintas da história evolutiva recente do Sistema Pinguela-Palmital-Malvas.

Inicialmente, no período com amplitude temporal circunscrita, nas datações mais próximas da base (4.600 \pm 70 e $3.950 \pm 70$ anos AP), ocorre alternância entre estratos compostos pela preponderância de espécies mixohalinas e intervalos caracterizados pela supremacia de espécies dulciaquícolas em um contexto transgressivo. Ali, os registros determinados por Actinocyclus normanii refletem períodos de clima mais seco, quando o volume de água doce drenado para a bacia era menor e a evaporação mais intensa. De forma inversa, Aulacoseira cf. agassizii determinou o esclarecimento de etapas de incremento do afluxo lótico por variação positiva do regime pluviométrico.

Após $3.950 \pm 70$ anos AP, alterações sedimentológicas e bióticas significativas como o estabelecimento de fácies com predomínio de areia, e a maior diversidade e abundância de vestígios de espécies perifíticas, caracterizaram o início do registro do processo de regressão holocena na planície costeira gaúcha.

No intervalo M22 (381,7 cm) Pseudopodosira echinus caracteriza o final da fase transgressiva para a seção. Em M44 (277,6 cm), o predomínio de Cyclotella choctawhatcheeana constituiu a culminância de pulso transgressivo iniciado em M42 $(287,1 \mathrm{~cm})$.

0 rebaixamento agudo da coluna d'água entre M29 (348,6 cm) e M32 (334,4 cm) indica a propensão de clima mais seco nestes níveis, em um contexto de aproximação do ponto de amostragem em direção à margem, encetado após M24 $(372,2 \mathrm{~cm})$ e que perdurou até o nível M39 (301,3 cm). A oscilação negativa do nível d'água da paleolaguna também foi detectada na intermitência de M45 $(272,9 \mathrm{~cm})$ a M47 $(263,5 \mathrm{~cm})$ e $\operatorname{M} 58(211,4 \mathrm{~cm})$ a $\operatorname{M63}(187,87 \mathrm{~cm})$.

Uma expressiva queda da influência do ambiente oceânico e maior aporte de água doce, indicado pelo aumento da abundância de Aulacoseira cf. agassizii, e declínio de espécies perifíticas mixohalinas foi verificada entre os níveis M48 (258,7 cm) e M55 (225,6 cm), devido, provavelmente, ao incremento pluviométrico atribuído ao retorno de período úmido na região.

A tendência de ressalinização do sistema em M56 $(220,9 \mathrm{~cm})$ e M57 $(216,2 \mathrm{~cm})$, com datação para 3.640 \pm 90 AP, foi correlacionada à elevação do nível relativo do mar referido para a costa brasileira aos 3.600 anos 
AP. A este, seguiu-se o rebaixe extremo da coluna d'água que culminou com um possível deslocamento do ponto de amostragem para a porção edáfica da margem entre M64 $(183,0 \mathrm{~cm})$ e M82 $(97,9 \mathrm{~cm})$, devido ao auge do recuo do nível relativo citado para 2.800 e 2.700 anos AP. Neste momento, instituiu-se uma comunicação mais restritiva com o oceano, conforme evidenciado pelo registro paleoflorístico que é retomado em função da transgressão marinha ocorrida aos 1.800 anos AP na PCNRS. Logo após, na configuração dos níveis finais do poço, destacam-se as espécies que compõem atualmente o fitoplâncton do Sistema Pinguela-Palmital-Malvas.

A manutenção da coerência das interpretações paleoambientais obtidas, quando confrontadas a estudos pregressos, e a detecção de processos originais para a região, assinalam a eficiência dos procedimentos estatísticos baseados no estabelecimento de agrupamentos significativos e destaque à espécies reguladoras destes particionamentos. Desta forma, indicam a possibilidade de adoção desta estratégia analítica como modelo em estudos paleoecológicos envolvendo diatomáceas recuperadas nos sedimentos inconsolidados dos depósitos holocenos da Planície Costeira Norte do Rio Grande do Sul, cuja extrapolação para outras áreas e épocas geológicas merece consideração.

Agradecimentos - Ao CNPq e ao Programa de Pós-graduação em Geociências da UFRGS pela concessão de bolsa de doutoramento (GH). À FAPERGS e ao Brasilien-Zentrum, nas pessoas de Marlene Junges, Wolf Engels e Sabine Heinle, pelo estágio de GH junto ao Departamento de Micropaleontologia da Universidade de Tübingen; Michal Kucera pela generosa acolhida e significativa orientação; Hartmut Schulz pelo treinamento e auxílio visando a preparação de amostras e obtenção de imagens em microscopia eletrônica de varredura na Universidade de Tübingen; Kerstin Braun pelo auxílio na obtenção das imagens em microscopia eletrônica de varredura; Wilfried Rönnfeld pela assistência na aquisição de imagens em microscopia óptica; Libuse Malik pelo suprimento de referências bibliográficas raras e de difícil acesso; Sérgio R. Dillenburg, Rodrigo R. Cancelli e Renato Backes Macedo pelo apoio na etapa de coleta e abertura do testemunho; Gilberto Silveira dos Santos pela realização das análises sedimentológicas; Cristina Moreira Félix, pelo auxílio na etapa de tratamento químico e preparação das amostras; Albano Schwarzbold, Eduardo Alexis Lobo Alcayaga e Sérgio R. Dillenburg pela expressiva contribuição como banca examinadora da tese que originou esta publicação.

\section{Referências}

Abrantes, F., Gil, I., Lopes, C. \& Castro, M. 2005. Quantitative diatom analyses - a faster cleaning procedure. Deep-SeaResearch I, 52: 189-198.

Abreu, V. dos S., Torgan, L.C., Esteves, I.R. F. \& Kotizran, S.C.B. 1987. Estudo paleogeográfico do Quaternário de Morretes, RS, Brasil. In: CONGRESSO DA ASSOCIAÇÃO BRASILEIRA DE ESTUDOS DO QUATERNÁRIO,1, Porto Alegre. Anais... p. 177-189.

Ângulo, R.J. \& Lessa, G.C. 1997. The Brazilian sea-level curves: A critical review with emphasis on the curves from Para- naguá and Cananéia regions. Marine Geology,140: 161166.

Ângulo, R.J., Giannini, P.C.F., Suguio, K. \& Pessenda, L.C.R. 1999. Relative sea-level changes in the last 5500 years in southern Brazil (Laguna-Imbituba region, Santa Catarina State) based on vermetid ${ }^{14} \mathrm{C}$ ages. Marine Geology,159: 323-339.

Battarbee, R.W., Jones, V.J., Flower, R.J., Cameron, N. G.,Bennion, H., Carvalho, L. \& Juggins, S. 2001. Diatoms. In: Smol, J.P., Birks, H. J. B. \& Last, W. M. (eds.). Tracking environmental change using lake sediments. V 3: Terrestrial, Algal, and Siliceous Indicators. Dordrecht: Kluwer Academic Publishers. p. 155 - 202.

Bennett, K.D. 1996. Determination of the number of zones in a biostratigraphical sequence. New Phytologist, 132: 155-170.

Bini, L.M. 2004. Análises multivariadas e limnologia: exploração, síntese e inferência de um mundo aquático complexo. In: Bicudo, C. E. M. \& Bicudo, D. C. (Orgs.). Amostragem em limnologia. São Carlos, RIMA, p. 73-107.

Callegaro, V.L.M. \& Lobo, E.A. 1990. Distribuição Horizontal da Comunidade de diatomáceas em Turfeiras Holocênicas da Planície Costeira do RS, BR. Pesquisas, Série Botânica, 2(1): 5-22.

Chalié, F. \& Gasse, F. 2002. Late Glacial-Holocene diatom record of water chemistry and lake level change from the tropical East African Rift Lake Abiyata (Ethiopia). Palaeogeography, Palaeoclimatology, Palaeoecology, 187: 259283.

Costa, C. B., Seeliger, U. \& Kinas, P.G. 1988. The effect of wind velocity and direction on the salinity regime in the Lower Patos Lagoon estuary. Ciência e Cultura, 40(9): 909-912.

Dias, J.L., Sad, A.R.E., Fontana, R.L. \& Feijó, F.J. 1994. Bacia de Pelotas. Boletim de Geociências da PETROBRAS, 8(1): 235245.

Douglas, M.S.V. \& Smol, J.P. 1999. Freshwater diatoms as indicators of environmental change in the High Artic. In: Stoermer, E.F. \& Smol, J.P. (eds.). The diatoms: Applications for Environmental and Earth Sciences. Cambridge: Cambridge University Press. p. 227-244.

Dufrêne, M.\& Legendre, P. 1997. Species assemblages and indicator species: the need for a flexible asymmetrical approach. Ecological Monographs, 67:345-366.

Florin, M-B. 1970. Late glacial diatoms of Kirchner Marsh, Southeastern Minnesota. Nova Hedwigia,31: 667-756.

Fluin, J., Gell, P., Haynes, D.,Tibby, J. \& Hancock, G. 2007.Paleolimnological evidence for the independent evolution foneighbouring terminal lakes, the Murray Darling Basin, Australia. Hydrobiologia, 591: 117-134.

Fürstenberger, C.B. \& Moro, R.S. 1998. Inferring lakewater characteristics in Lagoa Dourada, PR, Brazil, from surface sediment diatom assemblage data. Verhandlungen - Internationale Vereinigung für theoretische und angewandte Limnologie, 26: 1755-1757.

García-Rodriguez, F. \& Witkowski, A. 2003. Inferring sea level variation from relative percentages of Pseudopodosira kosugii in Rocha Lagoon, SE Uruguay. Diatom Research, 18(1): 49-59.

Gasse, F. 1986. East African Diatom. Taxonomy, ecological distribution. Bibliotheca Diatomologica,v. 11, J. Cramer, Stuttgart. 202 p.

Hartley, B. 1996. An Atlas of British Diatoms. Biopress Limited, Bristol, UK. 601 pp.

Hasenack, H. \& Ferraro, L. W. 1989. Considerações sobre o 
clima da região de Tramandaí, RS. Pesquisas, 22: 53-70.

Hasle, G.R. 1962. Three Cyclotellaspecies from marine localities studied in the light and electron microscopes. Nova Hedwigia, 4: 299-307.

Hasle, G.R. 1977. Morphology and taxonomy of Actinocyclu snormanii f. subsalsa (Bacillariophyceae). Phycologia, 16(3): 321-328.

Heusser, C.J. \& Streeter, S.S. 1980. A temperature and precipitation record for the past 16,000 years in southern Chile. Science, 210: 1345-1347.

Hustedt, F. 1927-1930. Die kieselalgen. In:Kryptogamen-Flora (L. Rabenhorst, ed.). Leipzig: Akademische Verlagsgesellschaf, v.7, pt.1, 920 p.

Hustedt, F. 1931-1959. Die Kieselalgen. In: KryptogramenFlora(L. Rabenhorst, ed.). Leipzig: Akademische Verlagsgesellschaf, v.7, pt.2, 845 p.

Hustedt, F. 1961-1966. Die Kieselalgen. In: KryptogramenFlora(L. Rabenhorst, ed.). Leipzig: Akademische Verlagsgesellschaf, v.7, pt.3, 816 p.

Hustedt, F. 1939. Die Diatomeenflora des Küstengebietes der Nordsee vom Dollart bis zur Elbemündung. I. Abhandlungen Naturwissenschaftlicher Verein zu Bremen, 31: 572-677.

Hustedt, F. 1937-1939. Systematische un ökologishe Untersuchungenüber den Diatomeen-Flora von Java, Bali, Sumatra. Archiv für Hydrobiologie, Supplement-Band, 15: 187 - 259.

Hustedt, F. 1942. Süsswasser-Diatomeen des indomalayischen Archipels und der Hawaii-Unseln. Internationale. Revue der Gesamten Hydrobiologie und Hidrographie,42(1/3): 1-252.

Hustedt, F. 1955. Marine littoral diatoms of Beaufort, North Carolina. Duke University Marine Station Bulletin, 6, 67 pp.

Hustedt, F. 1957. Die Diatomeenflora des Flusssystems der Weser im Gebiet der Hansestadt Bremen. Abhandlungen Naturwissenschaftlicher Verein zu Bremen, 34: 181-440.

Hustedt, F. 1959. Die Diatomeenflora der Unterwesser von der Lesummündung bis Bremerhaven mit Berücksichtigung des Unterlaufs der Hunte and Geeste. Veröffentlichungen des Institut für Meereforschung in Bremenhaven, 6:13-176.

Kingston, J.C. 2003.Araphid and monoraphid diatoms. In: Wehr, J. D. \& Sheath, R. G. (eds.). Freshwater algae of North America: Ecology and classification. London: Academic Press. p. 559 - 594.

Krammer, K. \& Lange-Bertalot, H. 1986. Bacillariophyceae. Teil 1: Naviculaceae. In: Ettl, H., Gerloff, J., Heyning, H. \& Mollenhauer, D. (eds). Süßwasserflora von Mitteleuropa, Stuttgart, Gustav Fisher, 876 p.

Krammer, K. \& Lange-Bertalot, H. 1988. Bacillariophyceae. Teil 2: Bacillariaceae, Epithemiaceae, Surirellaceae. In: Ettl, H.; Gerloff, J.; Heyning, H. \& Mollenhauer,D. (eds). Süßwasserflora von Mitteleuropa, Stuttgart, Gustav Fisher, $596 \mathrm{p}$.

Krammer, K. \& Lange-Bertalot, H. 1991a. Bacillariophyceae. Teil 3: Centrales, Fragilariaceae, Eunotiaceae. In: Ettl, H.; Gerloff, J.; Heyning, H. \& Mollenhauer,D. (eds). Süßwasserflora von Mitteleuropa, Stuttgart, Gustav Fisher, 576 p.

Krammer, K. \& Lange-Bertalot, H. 1991b. Bacillariophyceae. Teil 4: AchnanthaceaeNavicula(Linolatae) und Gomphonema.In: Ettl, H.; Gerloff, J.; Heyning, H. \& Mollenhauer,D. (eds). Süßwasserflora von Mitteleuropa, Stuttgart, Gustav Fisher Verlag, 437 p.

Krumbein, W.C. \& Pettijohn, F.J. 1938. Manual of Sedimentary Petrography. Appleton-Century-Crofts: New York. 594 p.

Legesse, D., Gasse, F., Radakovitch, O., Vallet-Coulomb, C.,
Bonnefille, R., Verschuren, D., Gibert, E. \& Barker, P. 2002. Environmental changes in a tropical lake (Lake Abiyata, Ethiopia) during recent centuries. Palaeogeography, $\mathrm{Pa}$ laeoclimatology, Palaeoecology,187: 233-258.

Lessa, G.C., Angulo, R.J., Giannini, P.C. \& Araújo, A.D. 2000. Stratigraphy and Holocene evolution of a regressive barrier in south Brazil. Marine Geology, 165: 87-108.

Long, A. 1992. Coastal responses to changes in sea level in the East Kent Fens and southeast England, UK, over the last 7,500 years. Proceedings of the Geologist's Association, 103: 187-199.

Lowe, R.L. 2003. Keeled and Canalled Raphid Diatoms. In: Wehr, J.D. \& Sheath, R.G. (eds.). Freshwater algae of North America: Ecology and classification. London: Academic Press. p. 559 - 594.

Ludwig, T.A.V. \& Bigunas, P.I.T. 2006.Bacillariophyta. . In: Bicudo, C.E.M. \& Menezes, M. (eds.). Gêneros de Algas de Águas Continentais do Brasil. São Carlos, RIMA, p. 391 - 449.

Machado, N.A.F. 2001. Planejamento ambiental aplicado às lagoas costeiras da bacia do Rio Tramandaí. São Carlos, Tese de Doutorado, Universidade Federal de São Carlos.

Marques-Toigo, M., Medeanic, S., Mosbrugger, V. \& Ashraf, A.R. 2002. Palaeoenvironmental changes in the Maquiné River Valley, RS, Brazil, during the Holocene according to palynological data. Revista Brasileira de Paleontologia, 3: 36-47.

Martin, L. \& Suguio, K. 1992. Variation of coastal dynamics during the last 7000 years recorded in beach ridge plains associated with river mouths: example from the Central Brazilian Coast. Paleogeography, Paleoclimatology, Paleoecology, 99: 119-140.

Mayewski, P.A., Rohling, E.C., Stager, J. C., Karlén, W., Maasch, K.A., Meeker, L.D., Meyerson, E.A., Gasse, F., van Kreveld, S., Holmgren, K., Lee-Thorp, J., Rosqvist, G., Rack, F., Staubwasser, M., Schneider, R.R. \& Steig, E.J. 2004. Holocene climate variability. Quaternary Research,62: 243-255.

McCune, B. \& Mefford, M.J. 1999. PC-ORD. Multivariate Analysis of Ecological Data, Version 4.MjM Software Design, Gleneden Beach, Oregon, USA. 237p.

Medeanic, S. \& Dillenburg, S.R. 2001. The Early Holocene palaeoenvironment history of the Tramandaí Lagoon (RS, Brazil). In: CONGRESSO DO QUATERNÁRIO DE PAÍSES DE LÍNGUA PORTUGUESA, 1, Portugal. Actas... p. 402-405.

Medeanic, S., Marques-Toigo, M. \& Ashraf, A.R. 2000a. The use of fossil algae for paleoenvironmental reconstruction during the late Holocene in the Maquiné River valley, RS, Brazil. Revista Universidade Guarulhos, Geociências, V: $168-172$.

Medeanic, S., Dillenburg, S.R \& Toldo Jr., E.E. 2000b. Palynological evidence of marine ingression in the Lagoa dos Patos Lagoon during the Late Holocene. Revista Universidade Guarulhos, Geociências, V: 141-145.

Medeanic, S., Dillenburg, S.R. \& Toldo Jr., E.E. 2001. Novos dados palinológicos da transgressão marinha pós-glacial em sedimentos da Laguna dos Patos, RS, Brasil. Revista Universidade Guarulhos, Geociências, VI(6): 64-76.

Medeanic, S.,Torgan, L.C., Clerot, L.C.P. \& Santos, C.B. 2009. Holocene Marine Transgression in the Coastal Plain of Rio Grande do Sul, Brazil: Palynomorph and Diatom Evidence. Journal of Coastal Research, 25: 224-233.

Melo, S., Torgan, L.C., Menezes, M. \& Correa Jr., J. D. 2006. First report of Cyclotella choctawhatcheeana (Bacillariophyta) from Brazilian tropical waters: ultrastructure and ecology. In: Eighteenth International Diatom Symposium, 2006, Miedzydroje. 
Procedinngs of the Eighteenth International Diatom Symposium 2004. Bristol : Biopress Limited, p. 293-299.

Metzeltin, D., Lange-Bertalot, H.\& García-Rodriguez, F., 2005. Diatoms from Uruguay. Lange-Bertalot, H. (ed.) Iconographia Diatomologica, v. 15. A.R.G. Gantner Verlag K.G., Ruggell, $736 \mathrm{p}$.

Meyer, K.E.B., Mendonça Filho, J.G., Ashraf, A.R., Souza, P.A. \& Reichhardt, K. 2005.Análise de Palinofácies em sedimentos Holocênicos da Lagoa dos Quadros, Rio Grande do Sul, Brasil. Revista Brasileira de Paleontologia, 8(1): 57-72.

Moreno, J.A. 1961. Clima do Rio Grande do Sul. Secretaria da Agricultura. Porto Alegre, RS, Brasil, 42 p.

Moro, R.S. \& Fürstenberger, C.B. 1997. Catálogo dos principais parâmetros ecológicos de diatomáceas não marinhas. Ponta Grossa: Editora UEPG, 282 p.

Nave, S., Freitas, P. \& Abrantes, F. 2001. Coastal upwelling in the Canary Island region: spatial variability reflected by the surface sediment diatom record. Marine Micropaleontology, 42: 1-23.

Odebrecht, C., Abreu, P.C., Möller Jr., O.O., Niencheski, L.A., Proença, L.A. \& Torgan, L.C. 2005. Drought effects on pelagic properties in the shallow and turbid Patos Lagoon, Brazil. Estuaries, 28(5): 675-685.

Pankow, H. 1976. Algenflora der Ostsee. II. Plankton. Veb Gustav Fisscher Verlag. Jena. 493 p.

Pappas, J.L. \& Stormer, E. F. 1996. Quantitative method for determining a representative algal sample count. Journal of Phycology, 32: 693-696.

Patrick, R.\& Reimer, C.W. 1966. The diatoms of the United States.Philadelphia: Livingston Publ., 688p.

Patrick, R.\& Reimer, C.W. 1975.The diatoms of the United States. Philadelphia: Livingston Publ., v.2, 213p.

Pedrozo, C.S. \& Rocha, O. 2007.Environmental Quality Evaluation of Lakes in the Rio Grande do Sul Coastal Plain. Brazilian Archives of Biology and Technology, 50(4): 673-685.

Pillar, V.D. 1994-2006. MULTIV - Multivariate Exploratory Analysis, Randomization Testing and Bootstrap Resampling. User's Guide versão 2. 1., 42 p.

Prasad, A.K.S.K., Nienow, J.A. \& Livingston, R.J. 1990. The genus Cyclotella (Bacillariophyta) in Choctaehatchee Bay, Florida, with special reference to $C$. striata and $C$. choctawhatcheeana sp. nov. Phycologia, 29(4): 418-436.

Romesburg, H.C. 1984. Cluster Analysis for Researchers. R. E. Krieger Publ. Co., Malabar, Florida. 334 p.

Round, F.E., Crawford, R.M. \& Mann, D.G. 1990.The Diatoms: Biology and morphology of the genera.Cambridge: Cambridge University Press. 747 p.

Salomoni, S.E. \& Schwarzbold, A. 2004. Phytoplankton community and limnological aspects of three polluted lakes, Marcelino, Peixoto and Pinguela, Osório, Rio Grande do Sul, Brazil. Biociências, 12(2):63-78.

Schwarzbold, A. \& Schäfer, A. 1984. Gênese e morfologia das lagoas costeiras do Rio Grande do Sul - Brasil. Amazoniana, IX(1):87-104.

Shepard, F.P. 1954. Nomenclature based on sand-silt-clay rations. Journal of Sedimentary Petrology, 24(3): 151-158.

Simonsen, R. 1962: Untersuchungen zur Systematik und Ökologie der Bodendiatomeen der westlichen Ostsee. Internationale Revue der gesamten Hydrobiologie, Systematische Beihefte,1:1-144.

Sterken, M.,Verleyen, E.,Sabbe, K.,Terryn, G.,Charlet, F., Bertrand, S.,Boës, X.,Fagel, N., De Batist, M. \& Vyverman, W. 2008. Late Quaternary climatic change in southern Chile, as recorded in a diatom sequence of LagoPuyehue
(40ㄴ4’ S). Journal of Paleolimnology, 39(2): 219-235.

Stoermer, E.F. \& Smol, J.P. 1999 The diatoms: applications for the environmental and earth sciences. Cambridge: University Press, 469 p.

Stoermer, E.F. \& Julius, M.L. 2003. Centric Diatoms. In: Wehr, J. D. \& Sheath, R. G. (eds.). Freshwater algae of North America: Ecology and classification. London: Academic Press. p. 559 - 594.

Sullivan, M.J. 1978. Diatom community structure: Taxonomic and statistical analysis of a Mississipi Salt Marsh. Journal of Phycology, 14:468-475.

Sundbäck, K. \& Medlin, L.K. 1986. A light and electron microscopic study of the epipsamic diatom CatenulaadhaerensMereschkowsky. Diatom Research, 1(2): 283-290.

Tanimura, Y. \& Sato, H. 1997. Pseudopodosirakosugii: a new Holocene diatom found to be a useful indicator to identify former sea-level. DiatomResearch, 12(2): 357-368.

Tomazelli, L.J. \&Villwock, J.A. 1991. Geologia do Sistema Lagunar Holocênico do Litoral Norte do Rio Grande do Sul, Brasil. Pesquisas,18(1):13-24.

Tomazelli, L.J. \&Villwock, J.A. 2000. O Cenozóico costeiro do Rio Grande do Sul. In: Holz, M. \& De Ros, L. F. (eds.). Geologia do Rio Grande do Sul. Porto Alegre: Edições CIGO/ UFRGS, p. 375-406.

Torgan, L.C. 1997. Estrutura e dinâmica da comunidade fitoplanctônica da laguna dos Patos, RS, Brasil em um ciclo anual. São Carlos, 248 p., Tese de Doutoramento, Universidade Federal de São Carlos.

Torgan, L.C. \& Biancamano, M.I. 1991. Catálogo das diatomáceas (Bacilariophyceae) referidas para o Estado do Rio Grande do Sul, Brasil, no período de 1973 a 1990. Caderno de Pesquisa, Série Botânica, 3(1): 1-201.

Torgan, L.C., Pillar, V.D. \&Niencheski, L.F. 2006. Phytoplankton associations of a costal lagoon in south of Brazil. Journal of Coastal Research, SI 39: 1149-1151.

Valentin, J.L. 2000. Ecologia numérica: uma introdução à análise multivariada de dados ecológicos. Rio de Janeiro: Interciência. 117 p.

Van Dam, H., Mertens A. \& Skindelam, J. 1994. A coded checklist and ecological indicator values of freshwaters diatoms from Netherlands. Netherland Journal of Aquatic Ecology, 28(1):117-133.

Villwock, J.A. 1984.Geology of the coastal province of Rio Grande do Sul, southern Brazil: A synthesis. Pesquisas,16: 5-49.

Villwock, J.A. \&Tomazelli, L.J. 1995. Geologia costeira do Rio Grande do Sul. Notas Técnicas, 8: 1-45.

Villwock, J.A.,Dehnhardt, E.A.,Loss, E.L. \&Hofmeister, T. 1980. Turfas da Provincia Costeira do Rio Grande do Sul: Geologia do Depósito Águas Claras. In: CONGRESSO BRASILEIRO DE GEOLOGIA, 31, Balneário Camboriú. Anais...p. 500-514.

Weschenfelder, J.,Medeanic, S., Corrêa, I.C.S. \&Aliotta, S. 2008. Holocene Paleoinlet of the Bojuru Region, Lagoa dos Patos, Southern Brazil. Journal of Coastal Research, 24 (1a):99-109. Witkowski, A., Lange-Bertalot, H. \& Metzeltin, D. 2000. Diatom flora of marine coasts I.In: H. Lange-Bertalot (ed.), Iconographia diatomologica. v. 7, 925p.

Manuscrito 491

Editor: Maria do Carmo Lima e Cunha. 


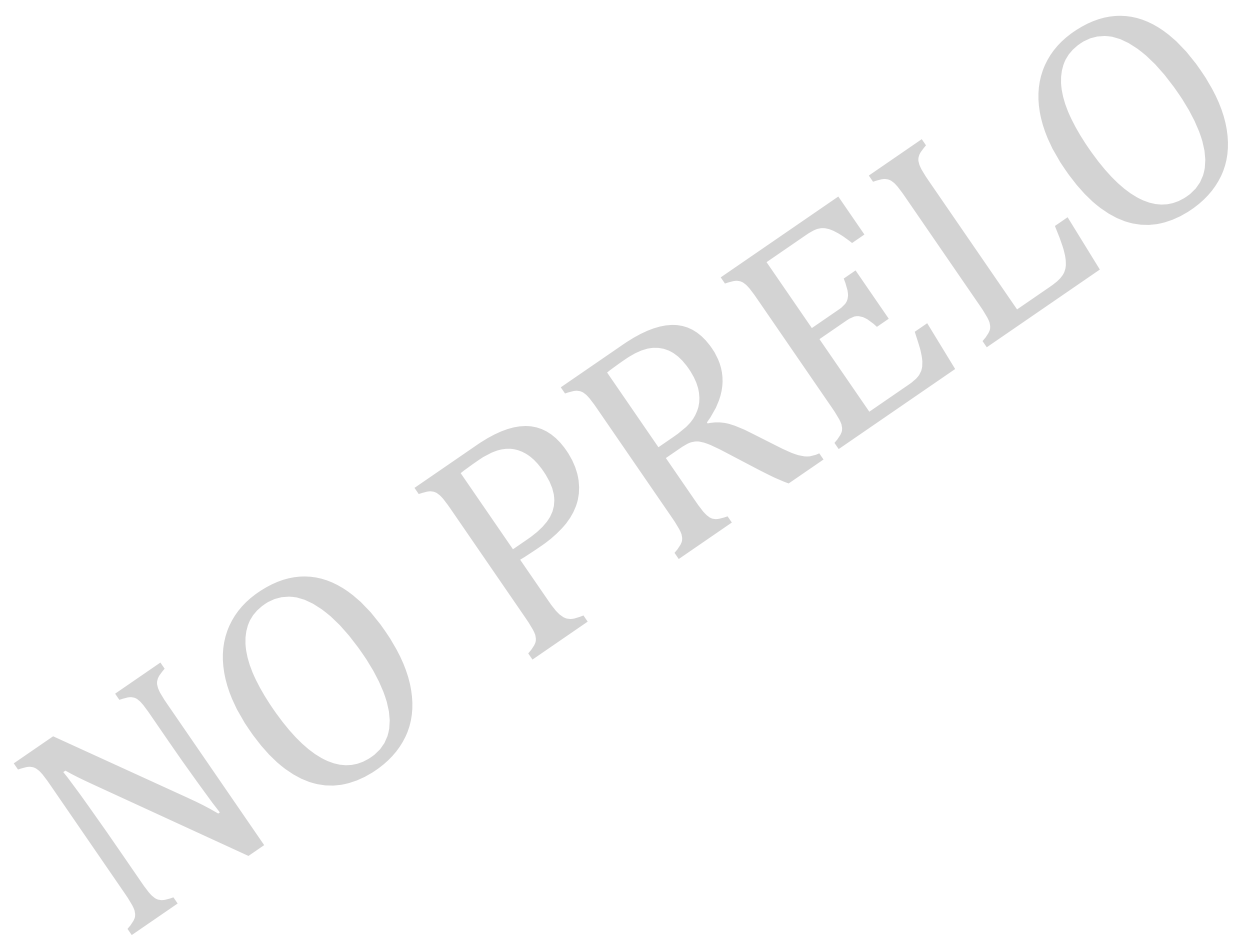

